Replacement of a 5-cm intrathoracic trachea with a tissue-engineered prosthesis in a canine model(Dissertation_全文)

\author{
$\operatorname{AUTHOR(S):~}$ \\ Ueda, Yuichiro
}

\title{
CITATION:
}

Ueda, Yuichiro. Replacement of a 5-cm intrathoracic trachea with a tissue-engineered prosthesis in a canine model. 京都大学, 2021, 博士(医学)

ISSUE DATE:

2021-09-24

URL:

https://doi.org/10.14989/doctor.k23470

RIGHT: 


\section{The Annals of Thoracic Surgery}

\section{Replacement of a 5-cm intrathoracic trachea with a tissue-engineered prosthesis in a canine model \\ --Manuscript Draft--}

\begin{tabular}{|c|c|}
\hline Manuscript Number: & ANNALS-20-04159R1 \\
\hline Article Type: & Original Article \\
\hline Section/Category: & General Thoracic \\
\hline Keywords: & $\begin{array}{l}\text { artificial trachea; intrathoracic tracheal replacement; pedicled omentum; neutral } \\
\text { atelocollagen }\end{array}$ \\
\hline Manuscript Classifications: & Airway; Animal model; Artificial organs; Tissue engineering; Trachea \\
\hline Corresponding Author: & $\begin{array}{l}\text { Toshihiko Sato, Ph.D. } \\
\text { Fukuoka University } \\
\text { Fukuoka, JAPAN }\end{array}$ \\
\hline First Author: & Yuichiro Ueda \\
\hline \multirow[t]{7}{*}{ Order of Authors: } & Yuichiro Ueda \\
\hline & Toshihiko Sato, PhD \\
\hline & Yojiro Yutaka, PhD \\
\hline & Tatsuo Nakamura, PhD \\
\hline & Seiichi Tanaka, PhD \\
\hline & Akinori Iwasaki, PhD \\
\hline & Hiroshi Date, PhD \\
\hline Manuscript Region of Origin: & JAPAN \\
\hline Abstract: & $\begin{array}{l}\text { Background: } \\
\text { Critical obstacles must be addressed before clinical application of artificial tracheas. } \\
\text { The major complications of long tracheal replacement include anastomotic dehiscence } \\
\text { and stenosis owing to poor vascularity and incomplete re-epithelialization. The } \\
\text { objective of this report was to clarify whether pre-incubation of the prosthesis in the } \\
\text { omentum could be applicable for reconstruction of a long segment of the intrathoracic } \\
\text { trachea in a canine model. } \\
\text { Methods: } \\
\text { The framework of an artificial trachea was fabricated from a polypropylene mesh tube } \\
\text { and coated with } 1 \% \text { neutral atelocollagen inside and outside the lumen. The prosthesis } \\
\text { was placed in the omentum of nine healthy male beagle dogs for } 3 \text { weeks. Then, the } \\
\text { pedicled prosthesis was used to replace a } 50 \text { mm long section of intrathoracic trachea. } \\
\text { Results were evaluated bronchoscopically, macroscopically, and histologically. } \\
\text { Results: } \\
\text { After } 3 \text { weeks of abdominal incubation, the prostheses were incorporated into the host } \\
\text { tissue. None of the dogs showed dehiscence of the anastomosis or infection of the } \\
\text { prostheses during the postoperative period. Seven of the nine dogs survived for more } \\
\text { than } 1 \text { year. One dog died of a bowel obstruction resulting from a diaphragmatic hernia } \\
3 \text { months after replacement, and another died due to reasons unrelated to the } \\
\text { prosthesis at } 6 \text { months. Bronchoscopic examination revealed no stenosis or } \\
\text { dehiscence, and microscopic examination of all dogs showed that the luminal surface } \\
\text { was covered by newly regenerated connective tissue and respiratory epithelium. } \\
\text { Conclusions: } \\
\text { Pedicled omentum-prosthesis complexes may allow successful reconstruction of a } \\
\text { long segment of the intrathoracic trachea. }\end{array}$ \\
\hline
\end{tabular}




\section{Replacement of a long segment of trachea with a fully vascularized prosthesis incubated in the omentum}

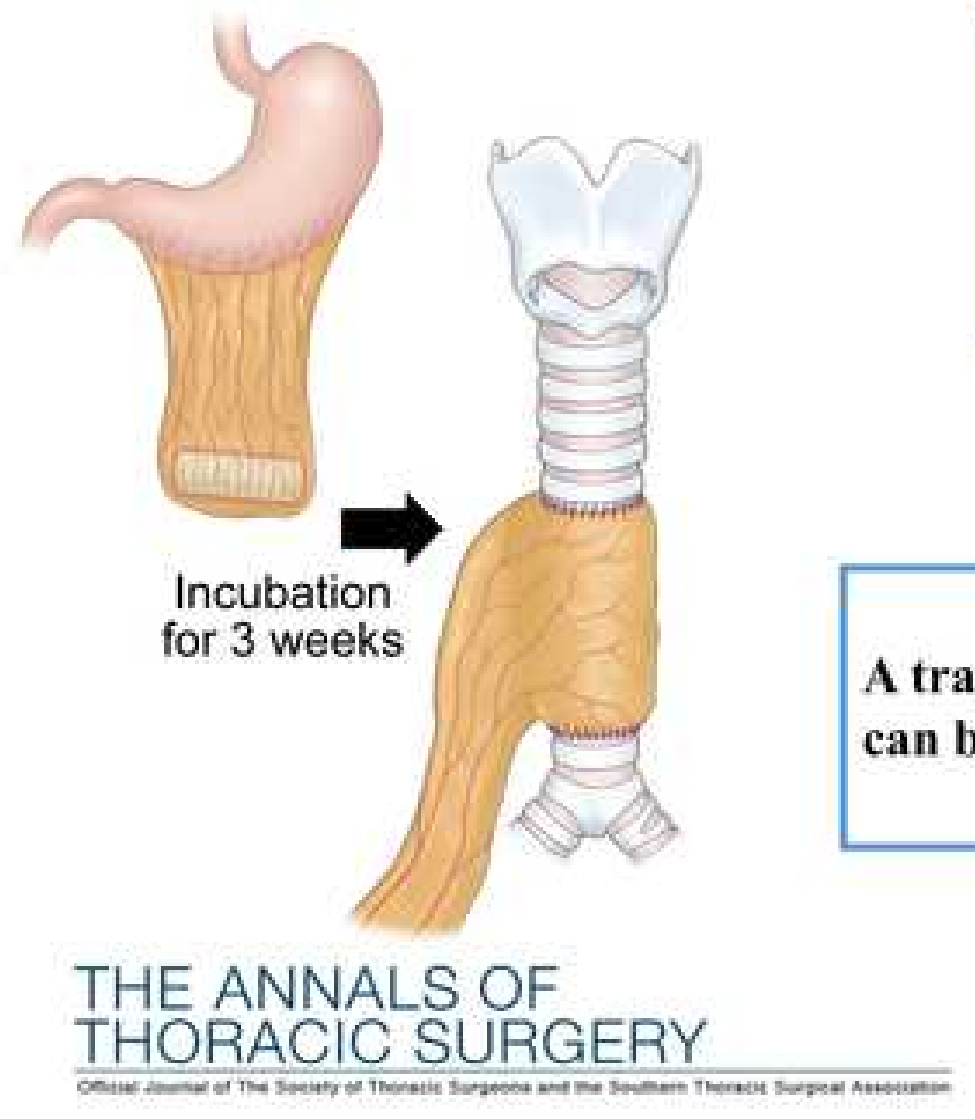

The problems with a long artificial trachea

- Dehiscence

- Stenosis

- Incomplete re-epithelialization

A tracheal prosthesis that was incubated in the omentum can be utilized for replacement of long segment of trachea

Sufficient blood flow

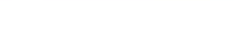


Title: Replacement of a 5-cm intrathoracic trachea with a tissue-engineered prosthesis in a canine model

\section{Running Head: Development of a long artificial trachea}

Authors: Yuichiro Ueda, $\mathrm{MD}^{12}$, Toshihiko Sato, $\mathrm{MD}, \mathrm{PhD}^{2 *}$, Yojiro Yutaka, $\mathrm{MD}, \mathrm{PhD}^{1}$, Tatsuo

Nakamura, $\mathrm{MD}, \mathrm{PhD}^{3}$, Seiichi Tanaka, DVM, $\mathrm{PhD}^{4}$, Akinori Iwasaki MD, $\mathrm{PhD}^{2}$, Hiroshi Date $\mathrm{MD}, \mathrm{PhD}^{1}$

\section{Authors' affiliations}

${ }^{1}$ Department of Thoracic Surgery, Kyoto University Graduate School of Medicine, Kyoto, Japan

${ }^{2}$ Department of General Thoracic Surgery, Breast and Pediatric Surgery, Fukuoka University School of Medicine, Fukuoka, Japan

${ }^{3}$ Department of Otolaryngology-Head and Neck Surgery, Graduate School of Medicine, Kyoto University, Kyoto, Japan

${ }^{4}$ Center for Experimental Animals, Fukuoka University, Fukuoka, Japan

\section{Classifications:}

Word count: 4495 
*Corresponding author: Toshihiko Sato

Department of General Thoracic Surgery, Breast and Pediatric Surgery, Fukuoka University

School of Medicine, 7-45-1 Nanakuma, Jonan-ku, Fukuoka 814-0180 Japan

E-mail: toshisato@fukuoka-u.ac.jp

Phone: +81-92-801-1011; Fax: +81-92-861-8271 


\section{ABSTRACT}

\section{Background:}

Critical obstacles must be addressed before clinical application of artificial tracheas. The major complications of long tracheal replacement include anastomotic dehiscence and stenosis owing to poor vascularity and incomplete re-epithelialization. The objective of this report was to clarify whether pre-incubation of the prosthesis in the omentum could be applicable for reconstruction of a long segment of the intrathoracic trachea in a canine model.

\section{Methods:}

The framework of an artificial trachea was fabricated from a polypropylene mesh tube and coated with $1 \%$ neutral atelocollagen inside and outside the lumen. The prosthesis was placed in the omentum of nine healthy male beagle dogs for 3 weeks. Then, the pedicled prosthesis was used to replace a $50 \mathrm{~mm}$ long section of intrathoracic trachea. Results were evaluated bronchoscopically, macroscopically, and histologically.

\section{Results:}

After 3 weeks of abdominal incubation, the prostheses were incorporated into the host tissue. None of the dogs showed dehiscence of the anastomosis or infection of the prostheses during the postoperative period. Seven of the nine dogs survived for more than 1 year. One dog died of a bowel obstruction resulting from a diaphragmatic hernia 3 months after replacement, and another 
died due to reasons unrelated to the prosthesis at 6 months. Bronchoscopic examination revealed no stenosis or dehiscence, and microscopic examination of all dogs showed that the luminal surface was covered by newly regenerated connective tissue and respiratory epithelium.

\section{Conclusions:}

Pedicled omentum-prosthesis complexes may allow successful reconstruction of a long segment of the intrathoracic trachea. 


\author{
Abbreviation and Acronym \\ SEM = scanning electron microscopy \\ DSA = digital subtraction angiography
}

\title{
INTRODUCTION
}

Tracheal reconstruction is a key procedure in the treatment of tracheal malignancies and benign tracheal stenosis. The maximum length that allows subsequent anastomosis to the native trachea is thought to be as long as 6-cm (1-2). A study in 901 patients reported that resections longer than $4 \mathrm{~cm}$ were associated with anastomosis failure and that wide range mobilization is mandatory for good coaptation (3). High tension at the anastomosis site can cause severe and fatal postoperative complications, such as dehiscence, making lengthy resections difficult for thoracic surgeons.

This limitation may be overcome by artificial tracheas. A tissue-engineered artificial trachea, consisting of a polypropylene mesh coated with an atelocollagen layer, was shown to be successful for airway reconstruction in canine models (4-8). The prosthesis was incorporated into the host tissue, resulting in regeneration of the ciliated epithelium over the mesh. The success of these preclinical studies has prompted applications for regulatory approval of this prosthesis for the repair of partial cervical tracheal defects in humans (9).

Despite clinical demands for "long segment" circumferential tracheal replacement (1), (10-12), 
replacement of a long segment of the trachea with an artificial trachea remains challenging. Replacement of the trachea, especially in the thoracic cavity, has several limitations. Unlike the cervical area, a prosthesis implanted into the thoracic cavity tends to be exposed in the area where surrounding tissue is sparse and blood supply is poor. This can leading to dissolution, air leakage, stenosis, and obstruction.

These problems can be addressed by using a self-incorporated prosthesis with rich blood flow. A prosthesis composed of a polypropylene framework coated with collagen, which was wrapped in the omentum and incubated in the abdominal cavity for 3 weeks, may result in better incorporation into host tissue. The omentum plays a key role in controlling inflammation and promoting revascularization, reconstruction, and tissue regeneration (13-16). In addition, culture of the tracheal scaffold in the omentum has been proved beneficial for rapid re-epithelialization and revascularization of the tissue-engineered trachea and the allograft(17-19). Our previous study showed that a $20 \mathrm{~mm}$ prosthesis incubated in the omentum resulted in successful tracheal replacement (20). However, longer prostheses are needed to meet clinical demands.

In this study, we examine whether it was feasible to replace a $50 \mathrm{~mm}$ long segment of the intrathoracic trachea in a canine model using a new methodological approach, involving the pedicled omentum.

\section{MATERIALS AND METHODS}




\section{Manufacture of the artificial trachea}

A collagen-conjugated bronchial prosthesis was constructed by a method similar to that reported previously (4), (7), (21-22). The framework consisted of a polypropylene mesh (Marlex mesh; CR Bard, Inc, Billerica, MA) cylinder, $60 \mathrm{~mm}$ long with an internal diameter of $20 \mathrm{~mm}$. The mesh was reinforced with a polypropylene supporting ring by thermal melt-bonding at 5-mm intervals and then fixed with 7-0 Prolene sutures (Ethicon, Inc, Somerville, NJ, Figure 1A). Following exposure of the framework to a corona discharge of $9 \mathrm{kV}$ for 5 minutes to render its surface hydrophilic for collagen immobilization, the framework was placed in a cylindrical Teflon mold with an inner diameter of $5 \mathrm{~cm}$ and a depth of $7 \mathrm{~cm}$. At the same time, a 5-mm-diameter polypropylene tube was inserted into the center of the prosthesis (Figure 1B). The collagen solution was poured into the space between the outer mold and the inner tube and then freezedried. During the freeze-drying process, the collagen cast adapted a porous structure with a pore size range from 100 to $500 \times 10^{-6} \mathrm{~m}$. The collagen-conjugated mesh was heated at $140^{\circ} \mathrm{C}$ under vacuum pressure for 6 hours to induce moderate cross-linking of the collagen molecules and prevent early breakdown of the collagen in vivo (Figure 1C and D).

\section{Determination of appropriate collagen conditions}

The collagen used in this study was atelocollagen, which had been extracted from young porcine skin by enzymatic treatment with pepsin (NMP collagen PS; Nippon Meatpackers, Ibaraki, Japan). 
The collagen mass ( $\mathrm{pH}$ 7.4) was made according to the manufacturer's protocol. Detailed protocols for the denatured collagen-based scaffold have been described previously (22). To compare the spatial structures at different concentrations, $1 \%$ and $3 \%$ collagen solutions were prepared and freeze-dried, yielding the collagen sponges. Scanning electron microscopy (SEM) showed that the structure made from 3\% collagen was denser than the structure made from $1 \%$ collagen (Figure 2A).

Two prostheses each consisting of $1 \%$ and $3 \%$ collagen were placed in the omentum of four dogs to determine the degree of self-incorporation and blood flow to the prostheses. After incubation for 3 weeks in the omentum, the prostheses were harvested. The prosthesis consisting of $1 \%$ collagen was completely incorporated into the omentum tissue (Figure 2B). The histological findings showed that the fatty tissues containing vessels covered the outside of the mesh and that connective tissue with an approximate thickness of $3 \mathrm{~mm}$ developed on the inside (Figure 2C). By contrast, the prosthesis consisting of $3 \%$ collagen was fragile and not incorporated into the host tissue (Figure 2D). Following the injection of contrast agent, diluted 10-fold (Iopamiron®300; Bayer-Schering Pharma, Berlin, Germany), into the gastroepiploic artery, digital subtraction angiography (DSA) was performed. DSA confirmed rich blood flow, including in the midportion, of the prosthesis consisting of $1 \%$ collagen (Video 1). The prosthesis consisting of $1 \%$ collagen was chosen for use in the subsequent tracheal reconstruction experiments. 


\section{Animals}

Adult beagle dogs weighing 7.5-10.6 kg were used in this study. All animals received humane care in compliance with the 2011 "Guide for the Care and Use of Laboratory Animals". The experimental protocol was approved by the Animal Experimental Committee of Kyoto University (approval No. R-18-81-2).

\section{Surgical procedures}

All surgical procedures were performed by a board-certified surgeon with over 8 years of experience. Each dog was sedated with an intramuscular injection of $0.05 \mathrm{mg} / \mathrm{kg}$ atropine sulfate, $10 \mathrm{mg} / \mathrm{kg}$ ketamine hydrochloride and $7 \mathrm{mg} / \mathrm{kg}$ xylazine and then intubated with an $8-\mathrm{mm}$ endotracheal tube. Mechanical ventilation was maintained using inhalational sevoflurane. A 500mg dose of ampicillin was injected intramuscularly prior to the skin incision. The implantation surgery was performed in two stages. The artificial trachea was wrapped into the lower portion of the omentum via median laparotomy (Figure 3A) and placed inside the abdominal cavity. The second operation was performed 3 weeks later. Following splenectomy, the left gastroepiploic artery was divided along the greater curvature of the stomach to obtain a sufficient length of pedicled omentum-prosthesis complexes, and the pedicle was guided to the right pleural cavity through the diaphragm. Following the resection of the azygos vein, the trachea was exposed through the right thoracotomy at the third intercostal space (Figure 3B). A $50 \mathrm{~mm}$ segment of the 
intrathoracic trachea was removed, and a flexible intubation tube was inserted into the distal cut end of the trachea to maintain ventilation and anesthesia. The prepared prosthesis was then interposed into the defect and telescopic anastomosis with interrupted suturing with 3-0 Vicryl (Ethicon, Inc., Somerville, NJ, USA) was performed to insert the native trachea $5 \mathrm{~mm}$ inside the artificial trachea (Figure 3C). The oral end of the native trachea was anastomosed to the prosthesis, followed by anastomosis of the caudal end (Figure 3D).

\section{Evaluation}

\section{Periodical bronchoscopic examinations}

At $1,3,6,12,18$, and 24 months and at the time of sacrifice, dogs were placed under general anesthesia and examined with a bronchoscope (model BF1T20; Olympus Optical Co Ltd, Tokyo, Japan).

\section{Histological examination}

The animals were euthanized using deep anaesthesia with an overdose of sodium pentobarbital.

The prosthesis and native trachea were resected en bloc for subsequent evaluation. Stenosis was defined as a greater than one-third reduction of tracheal luminal diameter. After macroscopic evaluation, the specimens were placed in $10 \%$ formaldehyde solution, embedded in paraffin blocks, and sectioned into $5 \mu \mathrm{m}$-thick slices, which were stained with hematoxylin and eosin for light microscopic examination. 


\section{Results}

\section{Clinical courses}

The results of the experiments are shown in Table 1. All nine dogs survived into the postoperative period without any apparent morbidity. One dog was sacrificed 3 months after tracheal replacement due to appetite and weight loss. An autopsy showed bowel obstruction due to diaphragmatic hernia, but no airway complication was observed. Another dog died 6 months after tracheal replacement with no symptoms. An autopsy revealed no evidence of airway problems and no cause of death was determined.

Two dogs were sacrificed at 12 months. Another dog was sacrificed at 16 months due to appetite and weight loss. One dog died suddenly at 30 months due to a hemorrhagic gastric ulcer. The autopsy of each these four dogs revealed no airway problems associated with the artificial trachea. The remaining dog was kept alive for further observation and its weight did not change significantly during the period of observation.

\section{Bronchoscopic examination}

Bronchoscopic examinations at 1 month revealed that the luminal surface of the prosthesis was composed of glossy and whitish tissue (Figure 4A). Angiogenesis on the luminal surface was observed from the anastomosis site (Figure 4B, Video 2). Neovascularization was confirmed at the center of the prosthesis 1 year after transplantation (Figure 4C). The prosthesis was 
incorporated into the native trachea in all dogs. Two of the nine dogs (No. 3 and 4) showed small mesh exposure (approximately $5 \mathrm{~mm} \times 5 \mathrm{~mm}$ ). However, there were no signs of local infection or granulation tissue formation. The two small exposed meshes did not change during follow up. None of these dogs showed dehiscence of the anastomosis, marked stenosis, airway obstruction, or infection of the prosthesis throughout the experimental period (Figure 5).

\section{Macroscopic and histologic examination}

One dog was sacrificed at 3 months due to appetite and weight loss, and its prosthesis was examined histologically. Macroscopic examination showed that the prosthesis had been incorporated into the native trachea and that its inner surface was covered with glossy tissue (Figure 6A and 6B). Histologic examination showed that the prosthesis was covered with regenerated connective tissue, including ciliated cells (Figure 7A), which extended from the anastomotic site to the middle of the prosthesis (Figure 7B and 7D). By contrast, the center of the prosthesis was covered with a monolayer of squamous epithelium (Figure 7C). Twelve months after replacement, the prosthesis was completely incorporated into the native trachea and there were no signs of infection or rejection in the thoracic cavity (Figure 8).

\section{Comment}

This study investigated a novel method of long segmental intrathoracic tracheal replacement using

a tissue-engineered artificial trachea in a canine model. The prosthesis, consisting of a 
polypropylene framework coated with collagen, was inserted into the omentum to allow selfincorporation and rich blood flow prior to tracheal replacement. All procedures were performed successfully, and there was no evidence of mortality or morbidity directly attributable to the implanted prosthesis. These results suggest that this methodological approach can be utilized for long segment intrathoracic tracheal replacement in patients.

Although Grillo et al. claimed that about half of the length of the trachea can be removed in adults (1), the range of possible airway reconstruction with direct end-to-end anastomosis is limited and longer tracheal reconstruction has been challenging. Owing to the inevitable excessive tension on the anastomosis site, patients are always at risk of dehiscence whenever they move or cough. To avoid excessive tension, patients must flex their necks for a certain period of time after surgery. These patients also may require suturing to hold their chin and fore-chest in place, which may be quite painful. Implantation of long artificial tracheas following long segmental resection may be safer and more acceptable to patients.

In constructing tissue-engineered tracheae, the scaffold should have sufficient mechanical strength to prevent collapse of the airways. For example, an autologous tissue-engineered trachea was designed, consisting of a silicone tube with nonwoven mesh of polyglycolic acid seeded with sheep nasal chondrocytes (23). Based on theories of tissue engineering, chondrocytes were incorporated to overcome the problem of an artificial trachea. Chondrocytes produce a cohesive 
sheet for tissue reconstruction, and trachea-like cartilage grafts can be constructed using this scaffold-free sheet, which is less immunogenic and more biocompatible (24-25). However, these scaffolds had poor mechanical strength, making it difficult for the chondrocytes to control the shape of the cartilage in vivo for a long period of time.

In another attempt, cryopreserved silicone-stented aortic allografts were implanted into six patients who underwent extensive tracheal replacement (26). Over the long-term, these grafts consistently showed centripetal shrinking after stent removal, with none of these six patients having a graft stiff enough to allow definitive stent withdrawal. Thus, these aortic allografts lack durability required of a functional trachea (27-28), in contrast to non-absorbable artificial frameworks. Efforts have therefore been made to develop tracheal replacements using nonabsorbable materials. Direct implantation of a silicone tube resulted, however, in the development of obstructive granulation tissue, as well as migration, and vascular erosion (29). The main problem with this prosthesis was its lack of incorporation into the host, frequently causing serious consequences.

Crucial conditions for an artificial trachea include a durable framework that preserves its mechanical properties and secures the lumen for a long period of time. We therefore utilized a non-absorbable framework made of fine polypropylene mesh with long-term mechanical support. Moreover, the collagen-coated prosthesis was made of mesh with a pore size of $300 \mu \mathrm{m}$, 
appropriate for cell infiltration and incorporation into the host tissue (30). Collagen has been widely utilized as a scaffold and can influence tissue regeneration. We previously showed that collagen (physiological $\mathrm{pH} 7.4$ ) denaturation at $140^{\circ} \mathrm{C}$ for $6 \mathrm{~h}$ produced a scaffold that was durable and biocompatible, with excellent cell infiltration ability (22). The mechanical strength of the scaffold can be controlled by changing the concentration of collagen. The prosthesis manufactured from $1 \%$ neutral collagen had moderate mechanical strength, minimizing foreignbody reaction during incubation. By contrast, the prosthesis consisting of 3\% collagen was stiff and could not be incorporated into host tissue because the dense collagen fibers constituted a barrier to cells invading the scaffold.

Replacement of a long segment of intrathoracic trachea with an artificial trachea is technically demanding, and postoperative complications occur frequently. Long grafts tend to show incomplete epithelization, necrosis, and proliferation of granulation tissue progressing to stenosis at their center (1). To improve the success rate, we utilized a method that would provide adequate blood supply to the tracheal grafts and complete self-incorporation at the time of implantation. Luminal stenosis and ulceration have been reported after long segment replacement (31-32). Omental wrapping of the anastomosis site resulted in increased blood flow, better epithelialization, and fewer complications (8). Split cryopreserved tracheal allo-transplantation, consisting of insertion of the omentum between two halves of grafts in an animal model, was found to prevent 
central graft necrosis, as well as ischemia, stenosis, or malacia, in contrast to control grafts that were simply covered with omental pedicles (33). These results indicated the importance of securing an adequate blood supply over the entire prosthesis. In the present study, DSA showed that blood supply from the omentum was sufficient for the entire prosthesis including the midportion. In addition, angiogenesis inside the luminal surface, including the middle portion of the prosthesis, was observed 1 year after implantation.

Pre-vascularized grafts may also prevent stenosis and improve re-epithelialization. For example, trachea wrapped in the omentum was kept in the peritoneal cavity of lung transplant recipients for 6 months prior to transplantation (34). Although that study did not employ the trachea, the implant was well vascularized. In an animal model, tracheal scaffolds were implanted into the sternohyoid muscle for 4 weeks to prevascularize the graft (35). Compared with unvascularized scaffolds, these prevascularized grafts wrapped in muscle flap demonstrated better epithelialization, as shown by the presence of a ciliated epithelium. This result suggested that timely revascularization could maintain cell viability and better regulate tissue formation. Our methodology was similar, suggesting that a firm framework with sufficient blood supply and complete self-incorporation is essential for preventing stenosis and securing the lumen.

This study had several limitations. First, this method is inapplicable for emergency treatment, as it requires a 3 week incubation period for cell infiltration and tissue regeneration prior to 
implantation. In addition, this method is invasive and stressful as the stomach must pull on the thoracic cavity to reposition the omentum and gastrointestinal motility may worsen when the vagus nerve is injured during tracheal resection. In addition, there is a possibility of bowel obstruction due to diaphragmatic hernia. Long-term studies are needed to determine the safety of this procedure.

In conclusion, this study describes a tracheal prosthesis that was fully vascularized and incorporated into the host tissue at the time of implantation. Replacement of long segment of trachea with this artificial trachea was successful in a canine experimental model. 


\section{Figure legends}

Fig. 1. Construction of the prosthesis.

(A) Illustration of the framework, showing a $60 \mathrm{~mm}$ long polypropylene mesh cylinder, with an internal diameter of $20 \mathrm{~mm}$ and reinforced with a polypropylene supporting ring.

(B) Illustration of the mold, showing the Teflon cylinder, with an internal diameter of $50 \mathrm{~mm}$ and a depth of $70 \mathrm{~mm}$ (white arrow). Red arrow, a 5-mm-diameter polypropylene tube.

(C), (D) Illustration of the freeze-dried 1\% collagen layers, placed both inside and outside the framework.

Fig. 2. Implantation of the prosthesis into the omentum

(A) SEM of 1\% (upper) and 3\% (lower) neutral collagen sponges.

SEM, Scanning electron microscopy

(B) Complete incorporation into the omentum of the prosthesis consisting of a 1\% neutral collagen sponge.

(C) Microscopic examination of a longitudinal section, showing that the omentum with vessels covered the outside of the mesh and that connective tissue developed with a thickness of approximately $3 \mathrm{~mm}$ on the inside of the mesh. Hematoxylin and eosin stain (original magnification $\times 1.25)$. $\mathrm{L}$, tracheal lumen; $\mathrm{M}$, mesh of the prosthesis.

(D) Lack of infiltration into host tissue of the prosthesis consisting of a 3\% neutral collagen sponge. This dense collagen fibers make the sponge too hard and brittle to incorporate into the omentum. 


\section{Fig. 3. Implantation of the prosthesis into the trachea.}

(A) Wrapping of the artificial trachea in pedicled omentum.

(B) Exposure of the intrathoracic trachea after resection of the azygos vein.

(C) Intraoperative view of tracheal reconstruction using pedicled omentum-prosthesis complexes with ventilation in the operative field.

(D) Resection of a $50 \mathrm{~mm}$ segment of trachea and telescopic anastomosis of the remaining trachea with the artificial trachea.

Fig. 4. Bronchoscopic views 1 month after the operation. Neither stenosis nor granulation was present and (A) the luminal surface of the prosthesis appeared glossy and whitish. (B) New blood vessels (arrow) extended from the native to the artificial trachea. (C) Neovascular was confirmed at the center of the lumen at 1 year after transplantation.

\section{Fig. 5.}

(A) Bronchoscopic findings following artificial trachea implantation. Ulceration was observed at the proximal anastomosis site 3 months after surgery.

(B) Regenerated mucosa in the tracheal lumen at the site of previous ulceration.

(C, D) Absence of stenosis and granulation over 2 years, along with complete coverage of the mesh by regenerated tissue.

Fig. 6. Macroscopic findings of the resected artificial trachea 3 months after implantation. 
(A) Complete incorporation of the prosthesis into the native trachea.

(B) Complete absence of stenosis.

\section{Fig. 7.}

(A) Microscopic examination of a longitudinal sectionstained with hematoxylin and eosin (original magnification $\times 2$ ). $(\mathbf{B}, \mathbf{D})$ Enlargement of the square areas marked $b$ and $d$ in $(A)$, showing regenerated cilia near the anastomosis site and continuity with the native bronchial epithelia. Hematoxylin and eosin staining (original magnification $\times 40$ ). (C) Enlargement of the square area marked $\mathrm{c}$ in $(\mathrm{A})$, showing that the center of the prosthesis is covered with a monolayer of squamous epithelium. Hematoxylin and eosin staining (original magnification $\times 40)$. L, tracheal lumen; M, mesh of the prosthesis.

Fig. 8. Autopsy findings 1 year after replacement, showing incorporation of the prosthesis (arrow) into the native trachea and no signs of infection in the thoracic cavity.

Video. 1. Digital subtraction angiography of the prosthesis consisting of $1 \%$ collagen.

Video. 2. Bronchoscopic views of the lumen of the prosthesis 3 months after the operation.

\section{Acknowledgments and Disclosures}

Authors have nothing to disclose with regard to commercial support. 


\section{References}

(1) Grillo HC. Tracheal replacement: a critical review. Ann Thorac Surg. 2002;73:1995-2004.

(2) Nakanishi R, Shirakusa T, Mitsudomi T. Maximum length of tracheal autografts in dogs. J

Thorac Cardiovasc Surg. 1993;106:1081-1087.

(3) Wright CD, Grillo HC, Wain JC, et al. Anastomotic complications after tracheal resection: prognostic factors and management. J Thorac Cardiovasc Surg. 2004;128:731-739.

(4) Nakamura T, Sato T, Araki M, et al. In situ tissue engineering for tracheal reconstruction using a luminar remodeling type of artificial trachea. J Thorac Cardiovasc Surg. 2009;138:811-819.

(5) Sato T, Araki M, Nakajima N, Omori K, Nakamura T. Biodegradable polymer coating promotes the epithelization of tissue-engineered airway prostheses. J Thorac Cardiovasc Surg. 2010;139:26-31.

(6) Sekine T, Nakamura T, Matsumoto K, et al. Carinal reconstruction with a Y-shaped collagenconjugated prosthesis. J Thorac Cardiovasc Surg. 2000;119:1162-1168.

(7) Okumura N, Nakamura T, Natsume T, Tomihata K, Ikada Y, Shimizu Y. Experimental study on a new tracheal prosthesis made from collagen-conjugated mesh. J Thorac Cardiovasc Surg. 1994;108:337-345.

(8) Teramachi M, Okumura N, Nakamura T, et al. Intrathoracic tracheal reconstruction with a collagen-conjugated prosthesis: evaluation of the efficacy of omental wrapping. $\mathrm{J}$ Thorac 
Cardiovasc Surg. 1997;113:701-711.

(9) Omori K, Tada Y, Suzuki T, et al. Clinical application of in situ tissue engineering using a scaffolding technique for reconstruction of the larynx and trachea. Ann Otol Rhinol Laryngol. 2008;117:673-678.

(10) Law JX, Liau LL, Aminuddin BS, Ruszymah BH. Tissue-engineered trachea: A review. Int J Pediatr Otorhinolaryngol. 2016;91:55-63.

(11) Gonfiotti A, Jaus MO, Barale D, et al. The first tissue-engineered airway transplantation: 5year follow-up results. Lancet. 2014;383:238-244.

(12) Abouarab AA, Elsayed HH, Elkhayat H, Mostafa A, Cleveland DC, Nori AE. Current Solutions for Long-Segment Tracheal Reconstruction. Ann Thorac Cardiovasc Surg. 2017;23:6675 .

(13) Kainuma S, Nakajima K, Miyagawa S, et al. Novel regenerative therapy combined with transphrenic peritoneoscopy-assisted omentopexy. Interact Cardiovasc Thorac Surg. 2018;26:993-1001.

(14) Shrager JB, Wain JC, Wright CD, et al. Omentum is highly effective in the management of complex cardiothoracic surgical problems. J Thorac Cardiovasc Surg. 2003;125:526-32.

(15) Collins D, Hogan AM, O'Shea D, Winter DC. The omentum: anatomical, metabolic, and surgical aspects. J Gastrointest Surg. 2009;13:1138-1146. 
(16) Platell C, Cooper D, Papadimitriou JM, Hall JC. The omentum. World J Gastroenterol. 2000;6:169-176.

(17) Hamaji M, Kojima F, Koyasu S, et al. Development of a composite and vascularized tracheal scaffold in the omentum for in situ tissue engineering: a canine model. Interact Cardiovasc Thorac Surg. 2014;19:357-362.

(18) Li J, Xu P, Chen H, Yang Z, Zhang Q. Improvement of tracheal autograft survival with transplantation into the greater omentum. Ann Thorac Surg. 1995;60:1592-1596.

(19) Li J, Xu P, Chen H. Successful tracheal autotransplantation with two-stage approach using the greater omentum. Ann Thorac Surg. 1997;64:199-202.

(20) Sakaguchi Y, Sato T, Muranishi Y, et al. Development of a novel tissue-engineered nitinol frame artificial trachea with native-like physical characteristics. J Thorac Cardiovasc Surg. 2018;156:1264-272.

(21) Teramachi M, Nakamura T, Yamamoto Y, Kiyotani T, Takimoto Y, Shimizu Y. Porous-type tracheal prosthesis sealed with collagen sponge. Ann Thorac Surg. 1997;64:965-969.

(22) Nakada A, Shigeno K, Sato T, Hatayama T, Wakatsuki M, Nakamura T. Optimal dehydrothermal processing conditions to improve biocompatibility and durability of a weakly denatured collagen scaffold. J Biomed Mater Res B Appl Biomater. 2017;105:2301-2307.

(23) Kojima K, Bonassar LJ, Roy AK, Vacanti CA, Cortiella J. Autologous tissue-engineered 
trachea with sheep nasal chondrocytes. J Thorac Cardiovasc Surg. 2002;123:1177-1184.

(24) Wu W, Cheng X, Zhao Y, Chen F, Feng X, Mao T. Tissue engineering of trachea-like cartilage grafts by using chondrocyte macroaggregate: experimental study in rabbits. Artif Organs. 2007;31:826-834.

(25) Tani G, Usui N, Kamiyama M, Oue T, Fukuzawa M. In vitro construction of scaffold-free cylindrical cartilage using cell sheet-based tissue engineering. Pediatr Surg Int. 2010;26:179-185. (26) Wurtz A, Porte H, Conti M, et al. Surgical technique and results of tracheal and carinal replacement with aortic allografts for salivary gland-type carcinoma. J Thorac Cardiovasc Surg. 2010;140:387-393.e2.

(27) Kim DH, Choi CB, Yang WJ, et al. Tracheal replacement with fresh and cryopreserved aortic allograft in adult dog. J Surg Res. 2012;175:199-206.

(28) Wurtz A, Hysi I, Zawadzki C, et al. Construction of a tube-shaped tracheal substitute using fascial flap-wrapped revascularized allogenic aorta. Eur J Cardiothorac Surg. 2012;41:663-668. (29) Neville WE, Bolanowski JP, Kotia GG. Clinical experience with the silicone tracheal prosthesis. J Thorac Cardiovasc Surg. 1990;99:604-612; discussion 12-3.

(30) Shimizu Y, Tamura K, Kato H, Teramatsu T, Hino T. Study on the artificial trachea using mesh. Jpn J Artif Organs 1983;486-489.

(31) Okumura N, Teramachi M, Takimoto Y, Nakamura T, Ikada Y, Shimizu Y. Experimental 
reconstruction of the intrathoracic trachea using a new prosthesis made from collagen grafted mesh. ASAIO J. 1994;40:M834-839.

(32) Liu Y, Lu T, Zhang Y, Qiao Y, Xi J, Wang Q. Collagen-conjugated tracheal prosthesis tested in dogs without omental wrapping and silicone stenting. Interact Cardiovasc Thorac Surg. 2016;23:710-715.

(33) Yokomise H, Inui K, Wada H, Ueda M, Hitomi S, Itoh H. Split transplantation of the trachea: a new operative procedure for extended tracheal resection. J Thorac Cardiovasc Surg. $1996 ; 112: 314-318$.

(34) Klepetko W, Marta GM, Wisser W, et al. Heterotopic tracheal transplantation with omentum wrapping in the abdominal position preserves functional and structural integrity of a human tracheal allograft. J Thorac Cardiovasc Surg. 2004;127:862-867.

(35) Luo X, Liu Y, Zhang Z, et al. Long-term functional reconstruction of segmental tracheal defect by pedicled tissue-engineered trachea in rabbits. Biomaterials. 2013;34:3336-3344. 
TABLE 1. Results of long segment intrathoracic tracheal reconstruction in individual dogs

\begin{tabular}{|c|c|c|c|c|c|}
\hline Dog no. & Stenosis & Dehiscence & Observation (months) & Epithelization & Remarks \\
\hline 1 & $(-)$ & $(-)$ & 3 & $100 \%$ & $\begin{array}{l}\text { Sacrificed at } 3 \text { months. Bowel obstruction due to diaphragmatic hernia } \\
\text { was detected. }\end{array}$ \\
\hline 2 & $(-)$ & $(-)$ & 6 & $100 \%$ & Sudden death at 6 months. There were no airway complications. \\
\hline 3 & $(-)$ & $(-)$ & 12 & $95 \%$ & $\begin{array}{l}\text { Sacrificed at } 12 \text { months. Small mesh exposure observed at the proximal } \\
\text { anastomosis site. }\end{array}$ \\
\hline 4 & $(-)$ & $(-)$ & 12 & $95 \%$ & $\begin{array}{l}\text { Sacrificed at } 12 \text { months. Small mesh exposure observed at the distal } \\
\text { anastomosis site. }\end{array}$ \\
\hline 5 & $(-)$ & $(-)$ & 14 & $100 \%$ & \\
\hline 6 & $(-)$ & $(-)$ & 16 & $100 \%$ & Sacrificed at 16 months due to appetite loss. \\
\hline 7 & $(-)$ & $(-)$ & 22 & $100 \%$ & \\
\hline 8 & $(-)$ & $(-)$ & 27 & $100 \%$ & \\
\hline 9 & $(-)$ & $(-)$ & 30 & $100 \%$ & Sudden death at 30 months due to a hemorrhagic gastric ulcer. \\
\hline
\end{tabular}




\section{A}

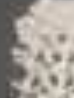

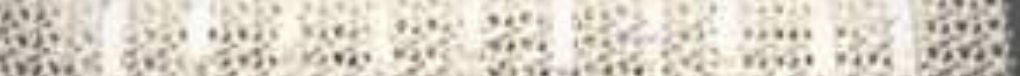

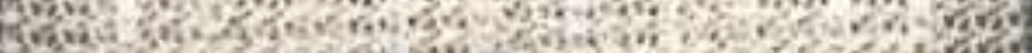

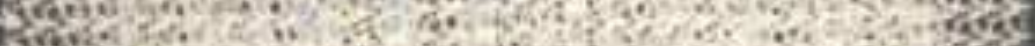

Weis:

w. 0 ars

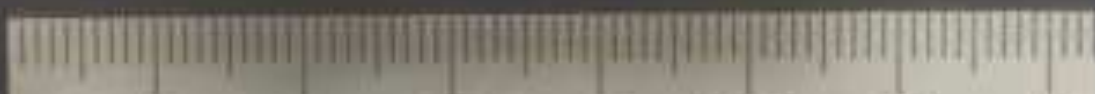

$$
10 \quad 20 \quad 30 \quad 40 \quad 50 \quad 60
$$

70

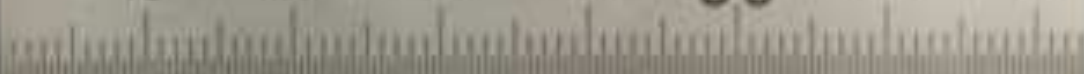

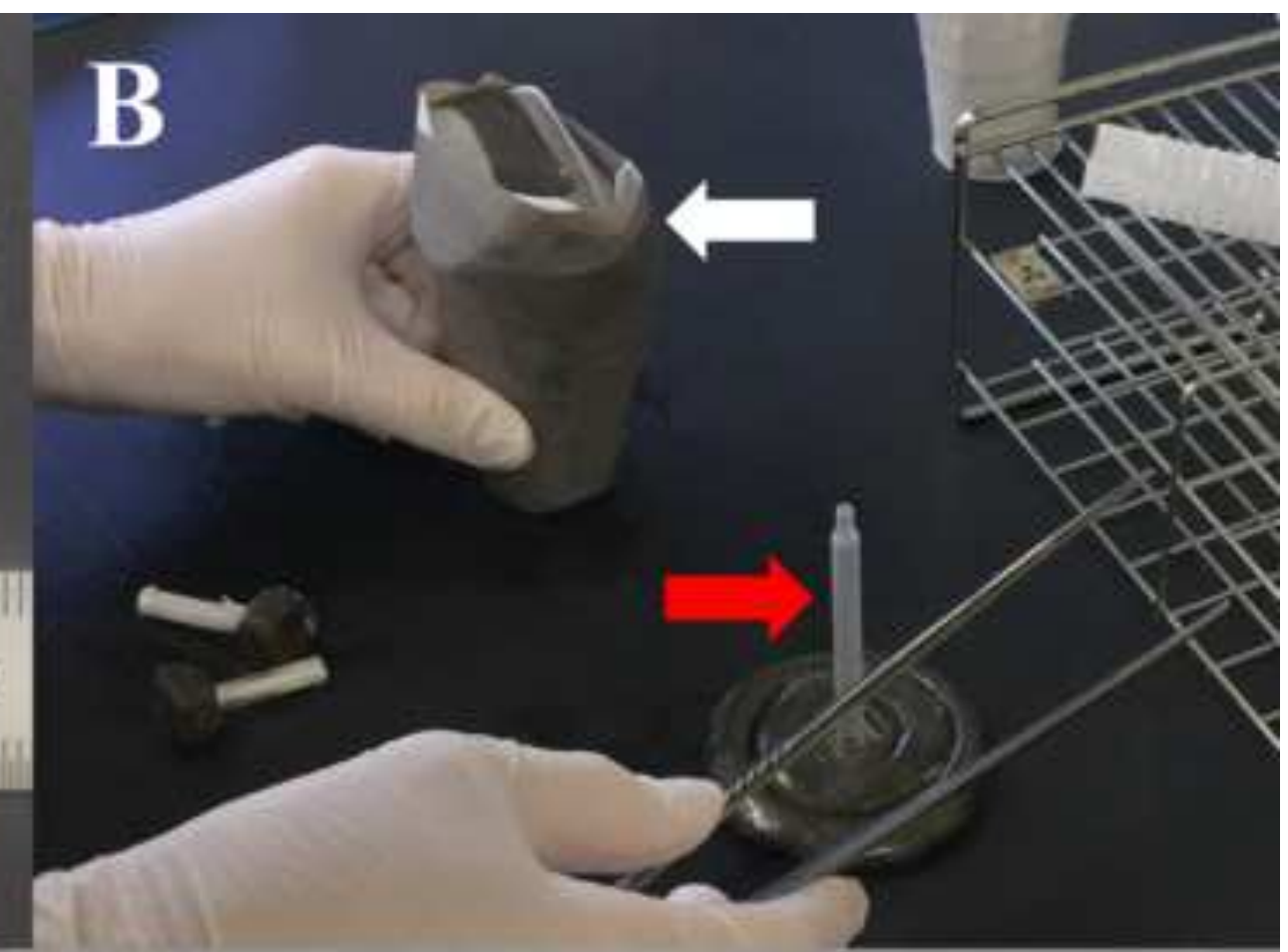

\section{C}

D

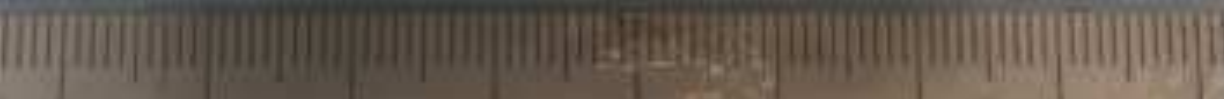

$10 \quad 20 \quad 30 \quad 40 \quad 50 \quad 60 \quad 70 \quad 80 \quad 90$

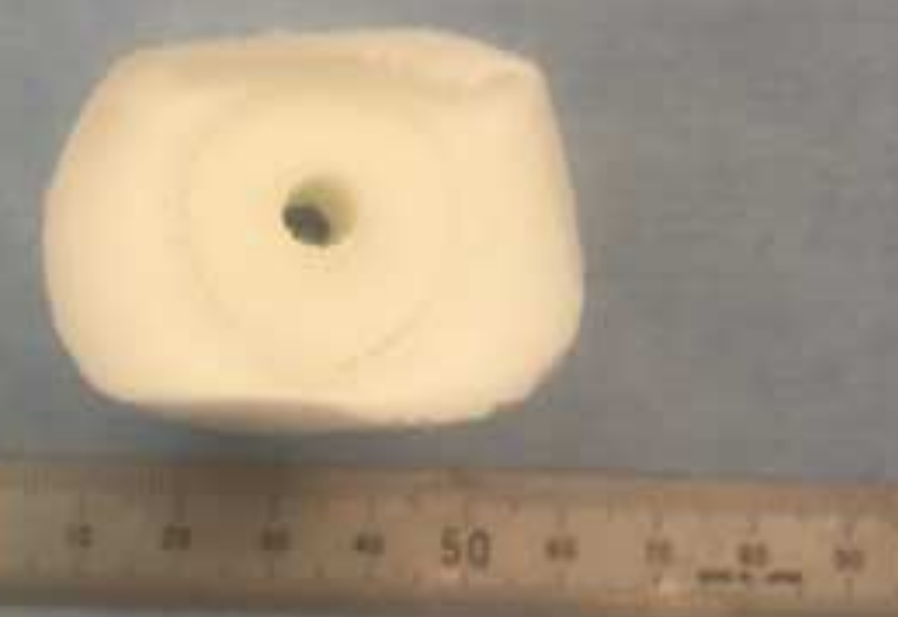

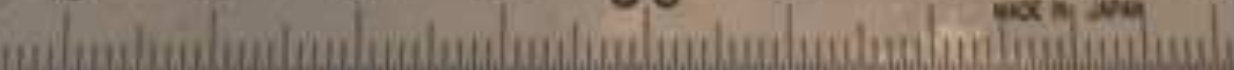



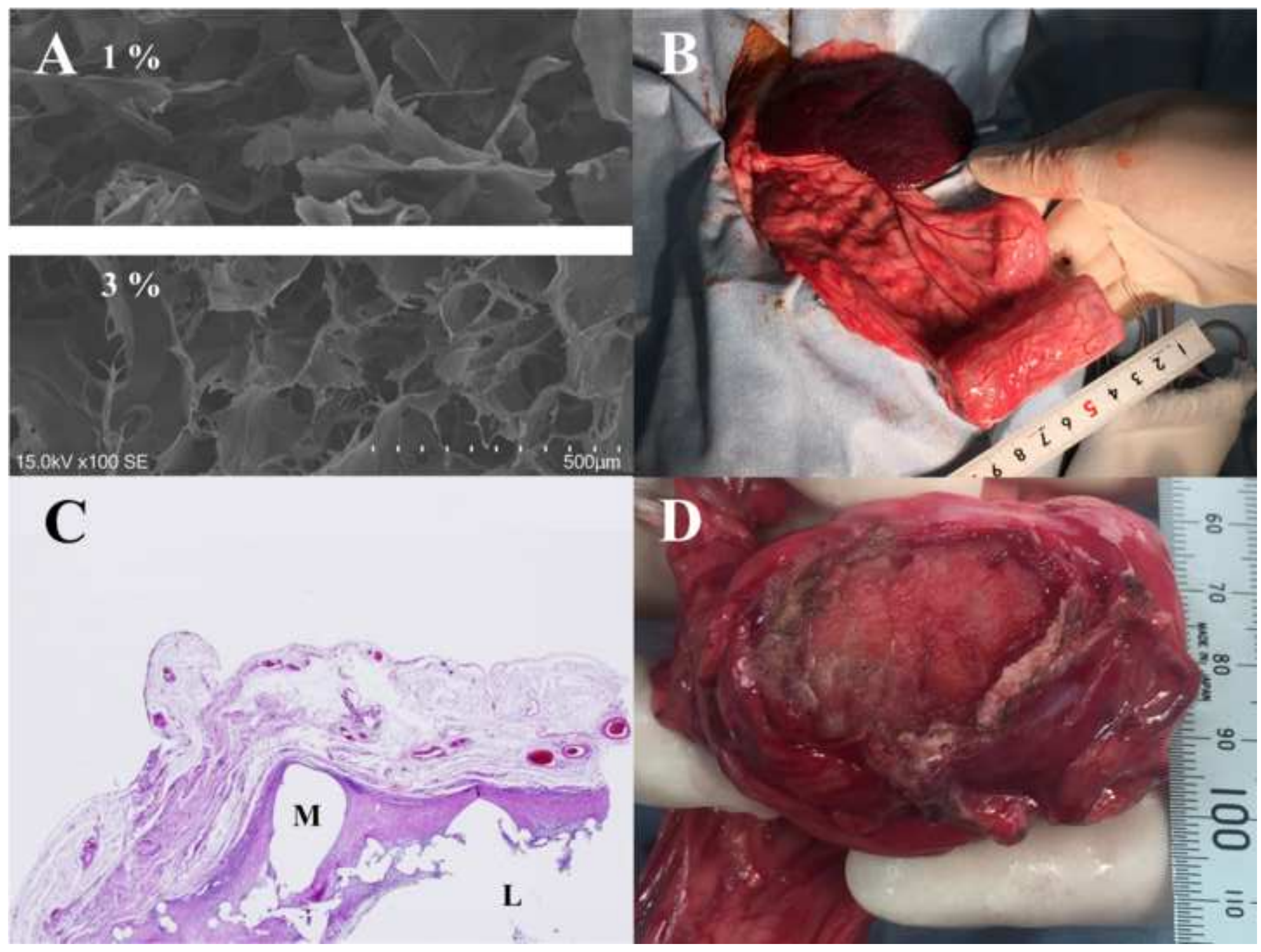
Click here to access/download;Figure;Figure3.tif $\stackrel{ \pm}{ }$
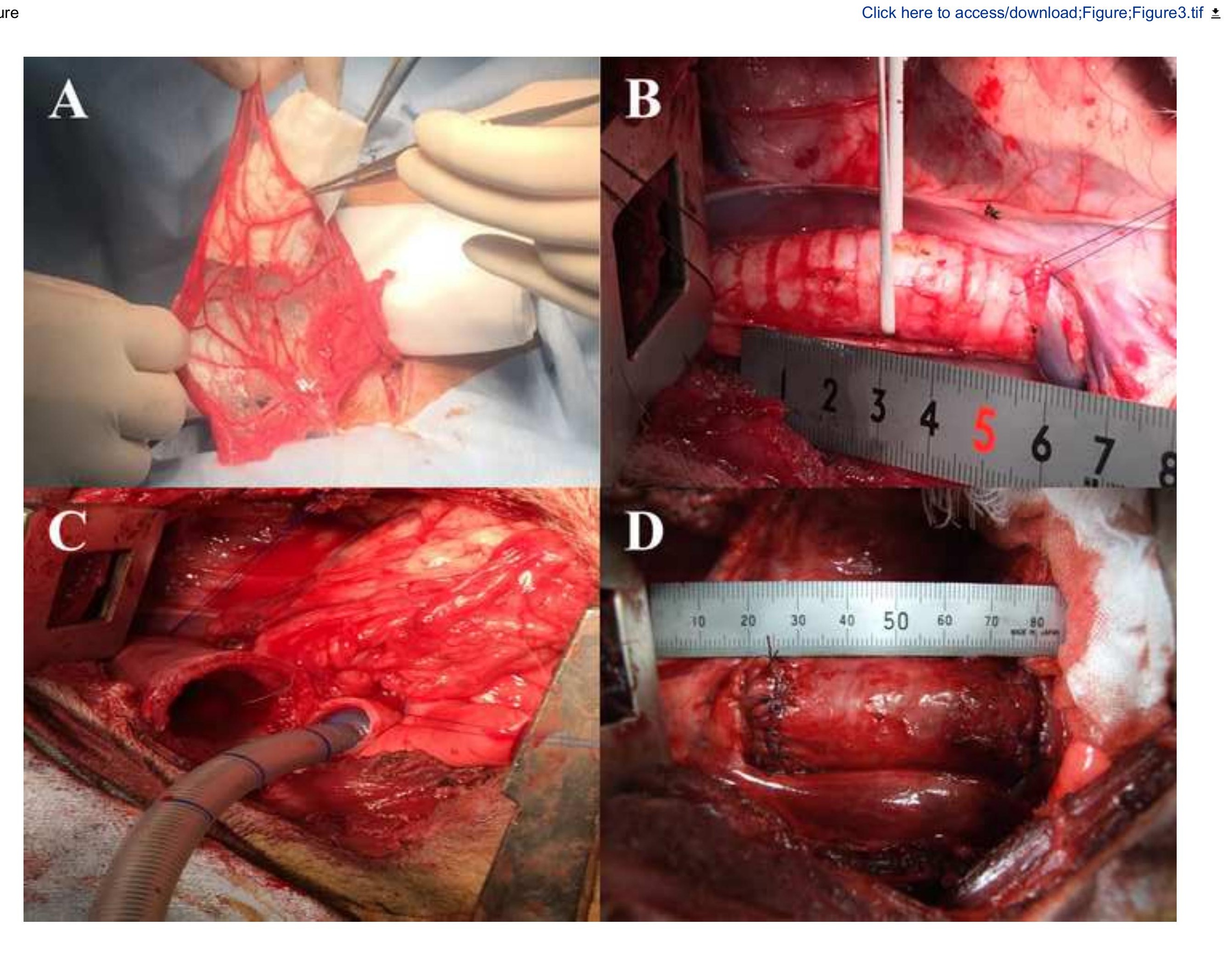
Click here to access/download;Figure;Figure4.tif $\stackrel{\star}{ }$
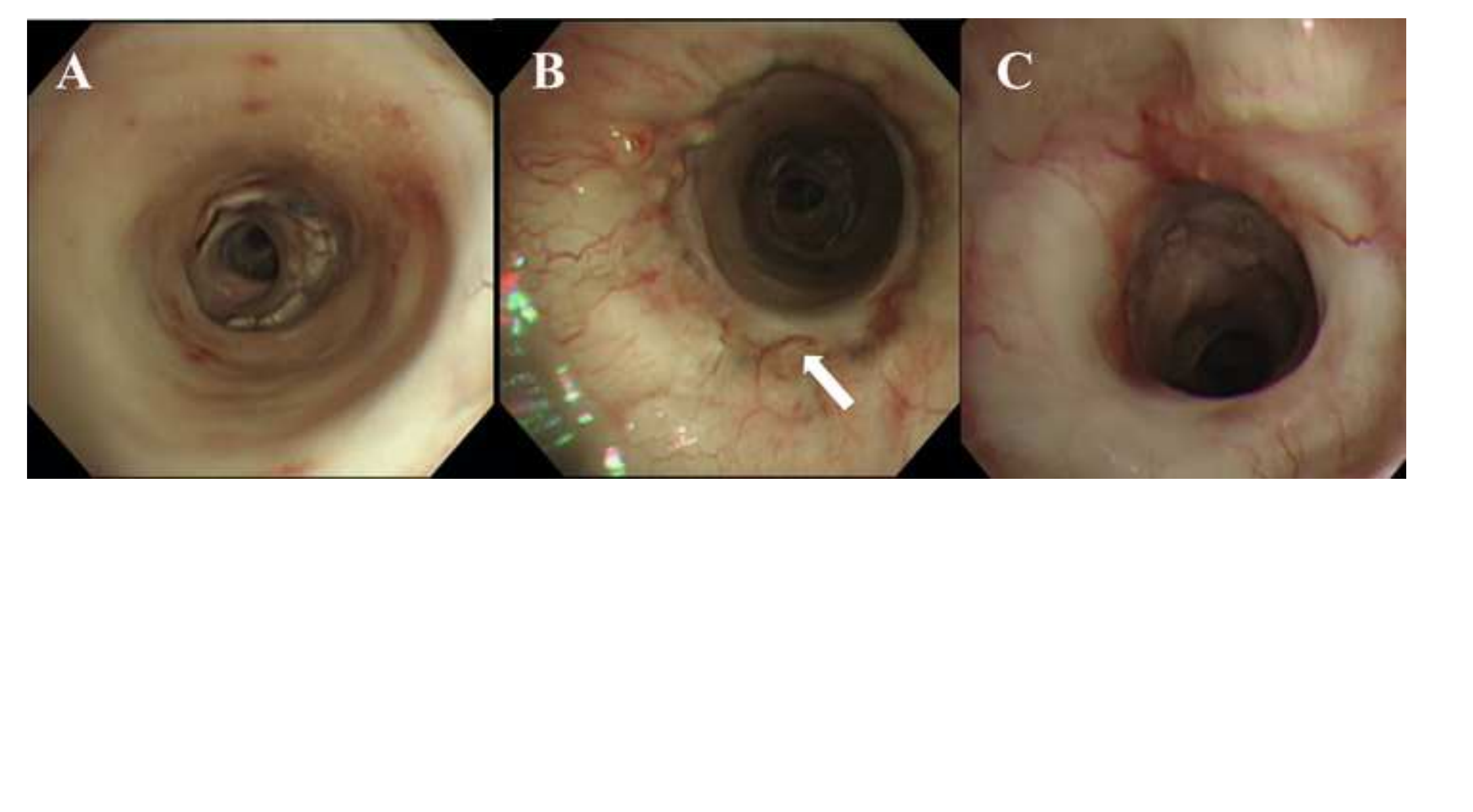


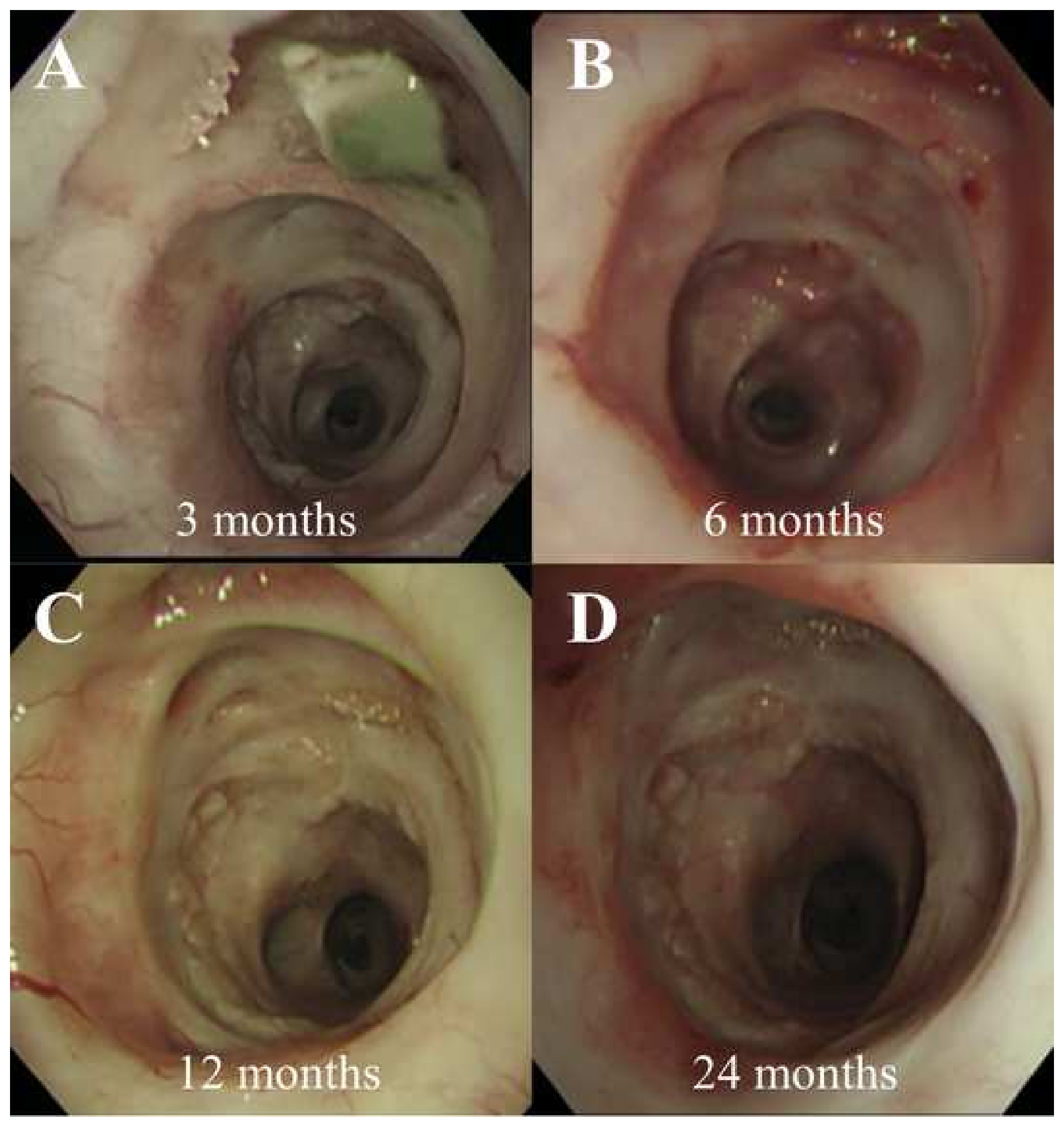




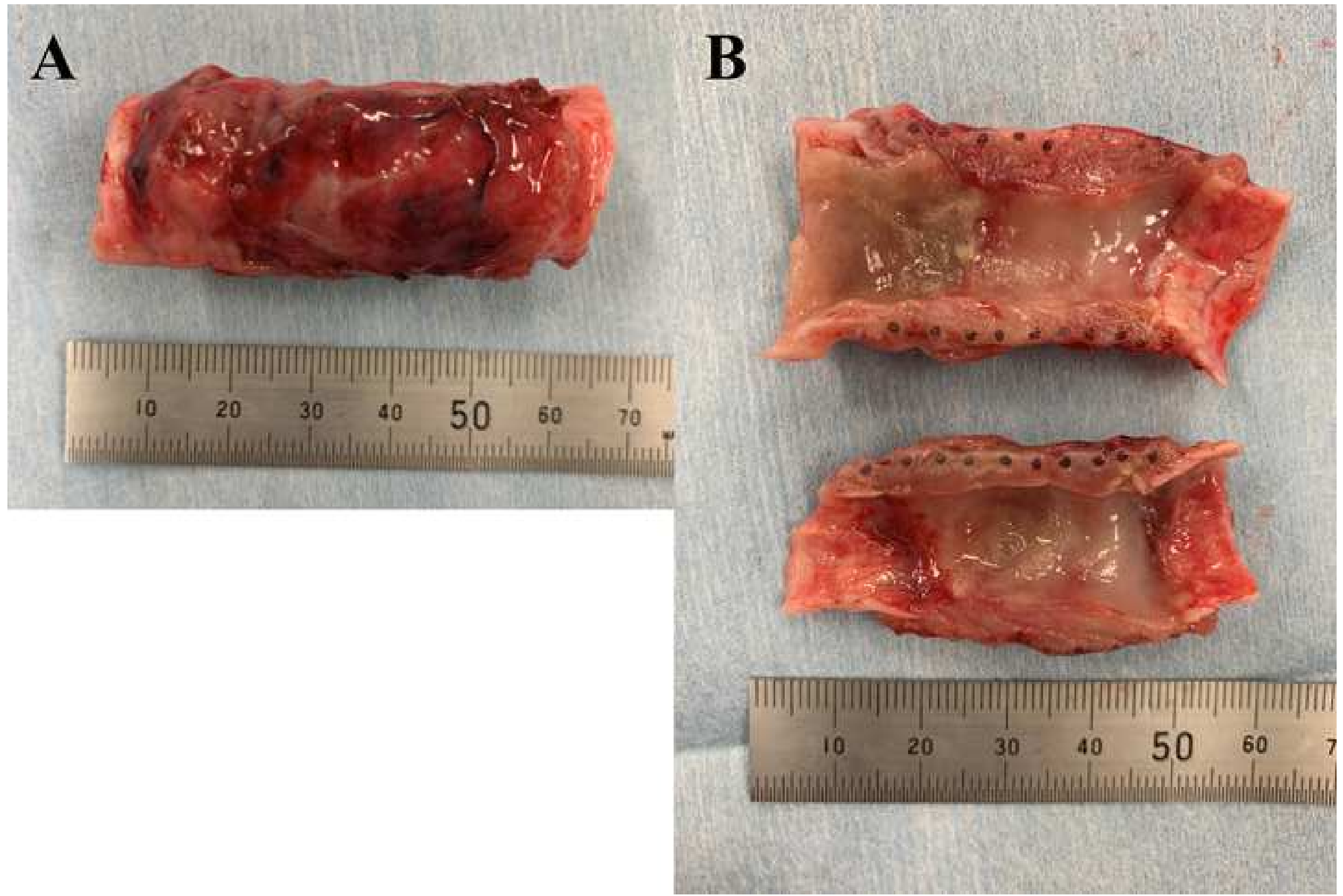

B

\section{.}




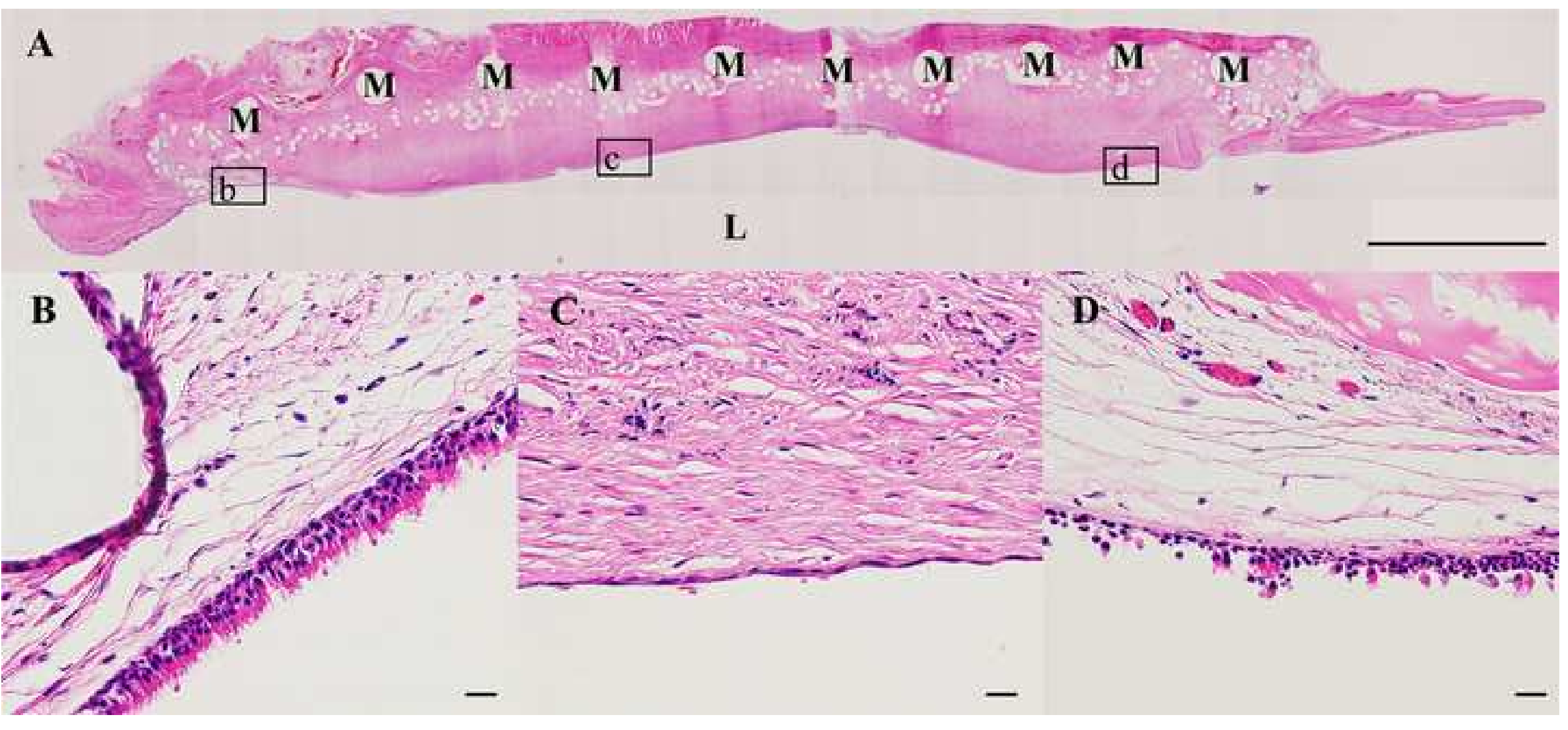




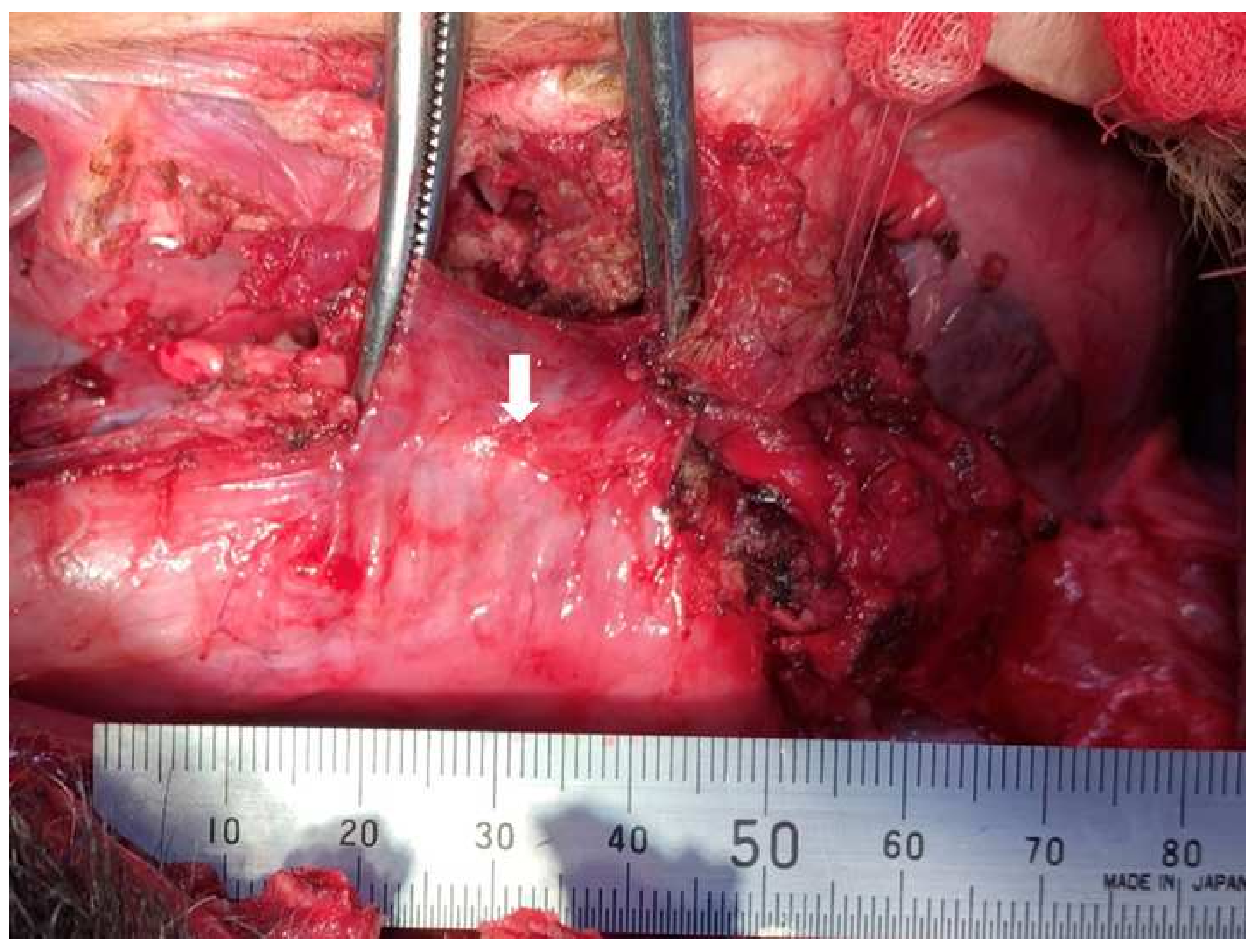


Click here to access/download Supplemental Video Video1.mp4 
Click here to access/download

\section{Supplemental Video Video 2.mp4}


Title: Replacement of a 5-cm intrathoracic trachea with a tissue-engineered prosthesis in a canine model

Running Head: Development of a long artificial trachea

Authors: Yuichiro Ueda, $\mathrm{MD}^{12}$, Toshihiko Sato, $\mathrm{MD}, \mathrm{PhD}^{2 *}$, Yojiro Yutaka, $\mathrm{MD}, \mathrm{PhD}^{1}$, Tatsuo Nakamura, $\mathrm{MD}, \mathrm{PhD}^{3}$, Seiichi Tanaka, DVM, $\mathrm{PhD}^{4}$, Akinori Iwasaki MD, $\mathrm{PhD}^{2}$, Hiroshi Date $\mathrm{MD}, \mathrm{PhD}^{1}$

\section{Authors' affiliations}

${ }^{1}$ Department of Thoracic Surgery, Kyoto University Graduate School of Medicine, Kyoto,

Japan

${ }^{2}$ Department of General Thoracic Surgery, Breast and Pediatric Surgery, Fukuoka University School of Medicine, Fukuoka, Japan

${ }^{3}$ Department of Otolaryngology-Head and Neck Surgery, Graduate School of Medicine, Kyoto University, Kyoto, Japan

${ }^{4}$ Center for Experimental Animals, Fukuoka University, Fukuoka, Japan

\section{Classifications:}

Word count: 4495 
*Corresponding author: Toshihiko Sato

Department of General Thoracic Surgery, Breast and Pediatric Surgery, Fukuoka University

School of Medicine, 7-45-1 Nanakuma, Jonan-ku, Fukuoka 814-0180 Japan

E-mail: toshisato@fukuoka-u.ac.jp

Phone: +81-92-801-1011; Fax: +81-92-861-8271 


\section{ABSTRACT}

Background:

Critical obstacles must be addressed before clinical application of artificial tracheas. The major complications of long tracheal replacement include anastomotic dehiscence and stenosis owing to poor vascularity and incomplete re-epithelialization. The objective of this report was to clarify whether pre-incubation of the prosthesis in the omentum could be applicable for reconstruction of a long segment of the intrathoracic trachea in a canine model.

\section{Methods:}

The framework of an artificial trachea was fabricated from a polypropylene mesh tube and coated with $1 \%$ neutral atelocollagen inside and outside the lumen. The prosthesis was placed in the omentum of nine healthy male beagle dogs for 3 weeks. Then, the pedicled prosthesis was used

to replace a $50 \mathrm{~mm}$ long section of intrathoracic trachea. Results were evaluated bronchoscopically, macroscopically, and histologically.

\section{Results:}

After 3 weeks of abdominal incubation, the prostheses were incorporated into the host tissue. None of the dogs showed dehiscence of the anastomosis or infection of the prostheses during the postoperative period. Seven of the nine dogs survived for more than 1 year. One dog died of a bowel obstruction resulting from a diaphragmatic hernia 3 months after replacement, and another 
died due to reasons unrelated to the prosthesis at 6 months. Bronchoscopic examination revealed

no stenosis or dehiscence, and microscopic examination of all dogs showed that the luminal surface was covered by newly regenerated connective tissue and respiratory epithelium.

\section{Conclusions:}

PThe pedicled omentum-prosthesis complexes may allow successful reconstruction of a long segment of the intrathoracic trachea. 


\section{Abbreviation and Acronym \\ SEM = scanning electron microscopy \\ DSA = digital subtraction angiography}

\section{INTRODUCTION}

Tracheal reconstruction is a key procedure in the treatment of tracheal malignancies and benign tracheal stenosis. The maximum length that allows subsequent anastomosis to the native trachea is thought to be as long as 6-cm (1-2). A study in 901 patients reported that resections longer than $4 \mathrm{~cm}$ were associated with anastomosis failure and that wide range mobilization is mandatory for good coaptation (3). High tension at the anastomosis site can cause severe and fatal postoperative complications, such as dehiscence, making lengthy resections difficult for thoracic surgeons.

This limitation may be overcome by artificial tracheas. A tissue-engineered artificial trachea, consisting of a polypropylene mesh coated with an atelocollagen layer, was shown to be successful for airway reconstruction in canine models (4-8). The prosthesis was incorporated into the host tissue, resulting in regeneration of the ciliated epithelium over the mesh. The success of these preclinical studies has prompted applications for regulatory approval of this prosthesis for the repair of partial cervical tracheal defects in humans (9).

Despite clinical demands for "long segment" circumferential tracheal replacement (1), (10-12), 
replacement of a long segment of the trachea with an artificial trachea remains challenging. Replacement of the trachea, especially in the thoracic cavity, has several limitations. Unlike the cervical area, a prosthesis implanted into the thoracic cavity tends to be exposed in the area where surrounding tissue is sparse and blood supply is poor. This can leading to dissolution, air leakage, stenosis, and obstruction.

These problems can be addressed by using a self-incorporated prosthesis with rich blood flow. A prosthesis composed of a polypropylene framework coated with collagen, which was wrapped in the omentum and incubated in the abdominal cavity for 3 weeks, may result in better incorporation into host tissue. The omentum plays a key role in controlling inflammation and promoting revascularization, reconstruction, and tissue regeneration (13-16). In addition, culture of the tracheal scaffold in the omentum has been proved beneficial for rapid re-epithelialization and revascularization of the tissue-engineered trachea and the allograft(17-19). Our previous study showed that a $20 \mathrm{~mm}$ prosthesis incubated in the omentum resulted in successful tracheal replacement (20). However, longer prostheses are needed to meet clinical demands.

In this study, we examine whether it was feasible to replacethe feasibility of replacement of a 50 $\mathrm{mm}$ long segment of the intrathoracic trachea in a canine model using a new methodological approach, involving the pedicled omentum.

\section{MATERIALS AND METHODS}




\section{Manufacture of the artificial trachea}

A collagen-conjugated bronchial prosthesis was constructed by a method similar to that reported previously (4), (7), (21-22). The framework consisted of a polypropylene mesh (Marlex mesh; CR Bard, Inc, Billerica, MA) cylinder, $60 \mathrm{~mm}$ long with an internal diameter of $20 \mathrm{~mm}$. The mesh was reinforced with a polypropylene supporting ring by thermal melt-bonding at 5-mm intervals and then fixed with 7-0 Prolene sutures (Ethicon, Inc, Somerville, NJ, Figure 1A). Following exposure of the framework to a corona discharge of $9 \mathrm{kV}$ for 5 minutes to render its surface hydrophilic for collagen immobilization, the framework was placed in a cylindrical Teflon motld with an inner diameter of $5 \mathrm{~cm}$ and a depth of $7 \mathrm{~cm}$. At the same time, a 5 -mm-diameter polypropylene tube was inserted into the center of the prosthesis (Figure 1B).entaining a collagen solution. The collagen solution was poured into the space between the outer mold and the inner tube and then freeze-dried.; During the freeze-drying process, the collagen cast adapted a porous structure with a pore size range from 100 to $500 \times 10^{-6} \mathrm{~m}$.and $\neq$ The collagen-conjugated Formatted: Superscript mesh was heated at $140^{\circ} \mathrm{C}$ under vacuum pressure for 6 hours to induce moderate cross-linking of the collagen molecules and prevent early breakdown of the collagen in vivo (Figure 1 $\underline{\mathrm{C} \text { and }}$ DB).

\section{Determination of appropriate collagen conditions}

The collagen used in this study was atelocollagen, which had been extracted from young porcine 
skin by enzymatic treatment with pepsin (NMP collagen PS; Nippon Meatpackers, Ibaraki, Japan).

The collagen mass ( $\mathrm{pH}$ 7.4) was made according to the manufacturer's protocol. Detailed protocols for the denatured collagen-based scaffold have been described previously (22). To compare the spatial structures at different concentrations, $1 \%$ and $3 \%$ collagen solutions were prepared and freeze-dried, yielding the collagen sponges. Scanning electron microscopy (SEM) showed that the structure made from 3\% collagen (Figure 1C) was denser than the structure made from $1 \%$ collagen (Figure $\underline{2 \mathrm{~A}} 1 \mathrm{H})$.

Two prostheses each consisting of $1 \%$ and $3 \%$ collagen were placed in the omentum of four dogs to determine the degree of self-incorporation and blood flow to the prostheses. After incubation for 3 weeks in the omentum, the prostheses were harvested. The prosthesis consisting of $1 \%$ collagen was completely incorporated into the omentum tissue (Figure $2 \underline{B} A)$. The histological findings showed that the fatty tissues containing vessels covered the outside of the mesh and that connective tissue with an approximate thickness of $3 \mathrm{~mm}$ developed on the inside (Figure 2C). By contrast, the prosthesis consisting of $3 \%$ collagen was fragile and not incorporated into the host tissue (Figure 2DBB). Following the injection of contrast agent, diluted 10-fold (Iopamiron ${ }^{\circledR} 300$; Bayer-Schering Pharma, Berlin, Germany), into the gastroepiploic artery, digital subtraction angiography (DSA) was performed. DSA confirmed rich blood flow, including in the midportion, of the prosthesis consisting of $1 \%$ collagen (Video 1). The prosthesis consisting 
of $1 \%$ collagen was chosen for use in the subsequent tracheal reconstruction experiments.

\section{Animals}

Adult beagle dogs weighing 7.5-10.6 kg were used in this study. All animals received humane care in compliance with the 2011 "Guide for the Care and Use of Laboratory Animals". The experimental protocol was approved by the Animal Experimental Committee of Kyoto University (approval No. R-18-81-2).

\section{Surgical procedures}

All surgical procedures were performed by a board-certified surgeon with over 8 years of experience. Each dog was sedated with an intramuscular injection of $0.05 \mathrm{mg} / \mathrm{kg}$ atropine sulfate, $10 \mathrm{mg} / \mathrm{kg}$ ketamine hydrochloride and $7 \mathrm{mg} / \mathrm{kg}$ xylazine and then intubated with an 8-mm endotracheal tube. Mechanical ventilation was maintained using inhalational sevoflurane. A 500mg dose of ampicillin was injected intramuscularly prior to the skin incision. The implantation surgery was performed in two stages. The artificial trachea was wrapped into the lower portion of the omentum via median laparotomy (Figure 3A) and placed inside the abdominal cavity. The second operation was performed 3 weeks later. Following splenectomy, the left gastroepiploic artery was divided along the greater curvature of the stomach to obtain a sufficient length of pedicled omentum-prosthesis complexes, and the pedicle was guided to the right pleural cavity through the diaphragm. Following the resection of the azygos vein, the trachea was exposed 
through the right thoracotomy at the third intercostal space (Figure 3B). A $50 \mathrm{~mm}$ segment of the intrathoracic trachea was removed, and a flexible intubation tube was inserted into the distal cut end of the trachea to maintain ventilation and anesthesia. The prepared prosthesis was then interposed into the defect and telescopic anastomosis with interrupted suturing with 3-0 Vicryl (Ethicon, Inc., Somerville, NJ, USA) was performed to insertsuch that the native trachea was inserted $5 \mathrm{~mm}$ inside the artificial trachea by interrupted suturing with $3-0$ Vicryl sutures (Ethicon, Ine., Somerville, NJ, USA)(Figure 3C). The oral end of the native trachea was anastomosed to the prosthesis, followed by anastomosis of the caudal end (Figure 3D).

\section{Evaluation}

\section{Periodical bronchoscopic examinations}

At $1,3,6,12,18$, and 24 months and at the time of sacrifice, dogs were placed under general anesthesia and examined with a bronchoscope (model BF1T20; Olympus Optical Co Ltd, Tokyo, Japan).

\section{Histological examination}

The animals were euthanized using deep anaesthesia withand an overdose of sodium pentobarbital.

The prosthesis and native trachea were resected en bloc for subsequent evaluation. Stenosis was defined as a greater than one-third reduction of tracheal luminal diameter. After macroscopic evaluation, the specimens were placed in $10 \%$ formaldehyde solution, embedded in paraffin 
blocks, and sectioned into $5 \mu \mathrm{m}$-thick slices, which were stained with hematoxylin and eosin for light microscopic examination.

\section{Results}

\section{Clinical courses}

The results of the experiments are shown in Table 1. All nine dogs survived into the postoperative period without any apparent morbidity. One dog was sacrificed 3 months after tracheal replacement due to appetite and weight loss. An autopsy showed bowel obstruction due to diaphragmatic hernia, but no airway complication was observed. Another dog died 6 months after tracheal replacement with no symptoms. An autopsy revealed no evidence of airway problems and no cause of death was determined.

Two dogs were sacrificed at 12 months. Another dog was sacrificed at 16 months due to appetite and weight loss. One dog died suddenly at 30 months due to a hemorrhagic gastric ulcer. The autopsy of each these four dogs revealed no airway problems associated with the artificial trachea. The remaining dog was kept alive for further observation and its weight did not change significantly during the period of observation.

\section{Bronchoscopic examination}

Bronchoscopic examinations at 1 month revealed that the luminal surface of the prosthesis was composed of glossy and whitish tissue (Figure 4A). Angiogenesis on the luminal surface was 
observed from the anastomosis site thard the center of the prosthesis-(Figure 4B, Video 2).

Neovascularization was confirmed at the center of the prosthesis 1 year after transplantation

(Figure 4C). The prosthesis was incorporated into the native trachea in all dogs. Two of the nine dogs (No. 3 and 4) showed small mesh exposure (approximately $5 \mathrm{~mm} \times 5 \mathrm{~mm}$ ). However, there were no signs of local infection or granulation tissue formation. The two small exposed meshes did not change during follow up. None of these dogs showed dehiscence of the anastomosis, marked stenosis, airway obstruction, or infection of the prosthesis throughout the experimental period (Figure 5).

\section{Macroscopic and histologic examination}

One dog was sacrificed at 3 months due to appetite and weight loss, and its prosthesis was examined histologically. Macroscopic examination showed that the prosthesis had been incorporated into the native trachea and that its inner surface was covered with glossy tissue (Figure 6A and 6B). Histologic examination showed that the prosthesis was covered with regenerated connective tissue, including ciliated cells (Figure 7A), which extended from the anastomotic site to the middle of the prosthesis (Figure 7B and 7D). By contrast, the center of the prosthesis was covered with a monolayer of squamous epithelium (Figure 7C). Twelve months after replacement, the prosthesis was completely incorporated into the native trachea and there were no signs of infection or rejection in the thoracic cavity (Figure 8). 


\section{Comment}

This study investigated a novel method of long segmental intrathoracic tracheal replacement using

a tissue-engineered artificial trachea in a canine model. The prosthesis, consisting of a polypropylene framework coated with collagen, was inserted into the omentum to allow selfincorporation and rich blood flow prior to tracheal replacement. All procedures were performed successfully, and there was no evidence of mortality or morbidity directly attributable to the implanted prosthesis. These results suggest that this methodological approach can be utilized for long segment intrathoracic tracheal replacement in patients.

Although Grillo et al. claimed that about half of the racheatlength of the trachea can be removed in adults (1), the range of possible airway reconstruction with direct end-to-end anastomosis is limited and longer tracheal reconstruction has been challenging. Owing to the inevitable excessive tension on the anastomosis site, patients are always at risk of dehiscence whenever they move or cough. To avoid excessive tension, patients must flex their necks for a certain period of time after surgery. These patients also may require suturing to hold their chin and fore-chest in place, which may be quite painful. Implantation of long artificial tracheas following long segmental resection may be safer and more acceptable to the-patients.

In constructing tissue-engineered tracheae, the scaffold should have sufficient mechanical strength to prevent collapse of the airways. For example, an autologous tissue-engineered trachea 
was designed, consisting of a silicone tube with nonwoven mesh of polyglycolic acid seeded with sheep nasal chondrocytes (23). Based on theories of tissue engineering, chondrocytes were incorporated to overcome the problem of an artificial trachea. Chondrocytes produce a cohesive sheet for tissue reconstruction, and trachea-like cartilage grafts can be constructed using this scaffold-free sheet, which is less immunogenic and more biocompatible (24-25). However, these scaffolds had poor mechanical strength, making it difficult for the chondrocytes to control the shape of the cartilage in vivo for a long period of time.

In another attempt, cryopreserved silicone-stented aortic allografts were implanted into six patients who underwent extensive tracheal replacement (26). Over the long-term, these grafts consistently showed centripetal shrinking after stent removal, with none of these six patients having a graft stiff enough to allow definitive stent withdrawal. Thus, these aortic allografts lack durability required of a functional trachea (27-28), in contrast to non-absorbable artificial frameworks. Efforts have therefore been made to develop tracheal replacements using nonabsorbable materials. Direct implantation of a silicone tube resulted, however, in the development of obstructive granulation tissue, as well as migration, and vascular erosion (29). The main problem with this prosthesis was its lack of incorporation into the host, frequently causing serious consequences.

Crucial conditions for an artificial trachea include a durable framework that preserves its 
mechanical properties and secures the lumen for a long period of time. We therefore utilized a non-absorbable framework made of fine polypropylene mesh with long-term mechanical support. Moreover, the collagen-coated prosthesis was made of mesh with a pore size of $300 \mu \mathrm{m}$, appropriate for cell infiltration and incorporation into the host tissue (30). Collagen has been widely utilized as a scaffold and can influence tissue regeneration. We previously showed that collagen (physiological $\mathrm{pH} 7.4$ ) denaturation at $140^{\circ} \mathrm{C}$ for $6 \mathrm{~h}$ produced a scaffold that was durable and biocompatible, with excellent cell infiltration ability (22). The mechanical strength of the scaffold can be controlled by changing the concentration of collagen. The prosthesis manufactured from $1 \%$ neutral collagen had moderate mechanical strength, minimizing foreignbody reaction during incubation. By contrast, the prosthesis consisting of $3 \%$ collagen was stiff and could not be incorporated into host tissue because the dense collagen fibers constituted a barrier to cells invading the scaffold.

Replacement of a long segment of intrathoracic trachea with an artificial trachea is technically demanding, and postoperative complications occur frequently. Long grafts tend to show incomplete epithelization, necrosis, and proliferation of granulation tissue progressing to stenosis at their center (1). To improve the success rate, we utilized a method that would provide adequate blood supply to the tracheal grafts and complete self-incorporation at the time of implantation. Luminal stenosis and ulceration have been reported after long segment replacement (31-32). 
Omental wrapping of the anastomosis site resulted in increased blood flow, better epithelialization,

and fewer complications (8). Split cryopreserved tracheal allo-transplantation, consisting of insertion of the omentum between two halves of grafts in an animal model, was found to prevent central graft necrosis, as well as ischemia, stenosis, or malacia, in contrast to control grafts that were simply covered with omental pedicles (33). These results indicated the importance of securing an adequate blood supply over the entire prosthesis. In the present study, DSA showed that blood supply from the omentum was sufficient for the entire prosthesis including the midportion. In addition, angiogenesis inside the luminal surface, including the middle portion of the prosthesis, was observed 1 yearduring the first month after implantation.

Pre-vascularized grafts may also prevent stenosis and improve re-epithelialization. For example, trachea wrapped in the omentum was kept in the peritoneal cavity of lung transplant recipients for 6 months prior to transplantation (34). Although that study did not employ the trachea, the implant was well vascularized. In an animal model, tracheal scaffolds were implanted into the sternohyoid muscle for 4 weeks to prevascularize the graft (35). Compared with unvascularized scaffolds, these prevascularized grafts wrapped in muscle flap demonstrated better epithelialization, as shown by the presence of a ciliated epithelium. This result suggested that timely revascularization could maintain cell viability and better regulate tissue formation. Our methodology was similar, suggesting that a firm framework with sufficient blood supply and 
complete self-incorporation is essential for preventing stenosis and securing the lumen.

This study had several limitations. First, this method is inapplicable for emergency treatment, as it requires a 3 week incubation period for cell infiltration and tissue regeneration prior to implantation. In addition, this method is invasive and stressful as the stomach must pull on the thoracic cavity to reposition the omentum and gastrointestinal motility may worsen when the vagus nerve is injured during tracheal resection. it requires surgery to prepare the scaffold with the omentum. In addition, there is a possibility of bowel obstruction due to diaphragmatic hernia. Long-term studies are needed to determine the safety of this procedure.

In conclusion, this study describes a tracheal prosthesis that was fully vascularized and incorporated into the host tissue at the time of implantation. Replacement of long segment of trachea with this artificial trachea was successful in a canine experimental model. 


\section{Figure legends}

\section{Fig. 1. Construction of the prosthesis.}

(A) Illustration of the framework, showing a $60 \mathrm{~mm}$ long polypropylene mesh cylinder, with an internal diameter of $20 \mathrm{~mm}$ and reinforced with a polypropylene supporting ring.

(A) $($ B) Illustration of the mold, showing the Teflon cylinder, with an internal diameter of 50

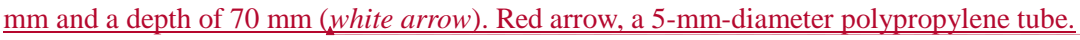

Formatted: Font: Italic

(B) (C), (D) Illustration of the freeze-dried 1\% collagen layers, placed both inside and outside the framework.

Formatted: Font: (Default) Times New Roman, Bold

Formatted: Normal, No bullets or numbering

(C) SEM of a $3 \%$ neutral collagen spenge.

(D) SEM of a $1 \%$ neutral collagen spenge.

SEM, S

Fig. 2. Implantation of the prosthesis into the omentum

(A) SEM of 1\% (upper) and 3\% (lower) neutral collagen sponges.

SEM, Scanning electron microscopy

Formatted: Font: Italic

Formatted: Font: Italic

(A) (B) Complete incorporation into the omentum of the prosthesis consisting of a $1 \%$ neutral

collagen sponge.

(C) Microscopic examination of a longitudinal section, showing that the omentum with vessels 
covered the outside of the mesh and that connective tissue developed with a thickness of

approximately $3 \mathrm{~mm}$ on the inside of the mesh. Hematoxylin and eosin stain (original

magnification $\times 1.25$ ). L, tracheal lumen; $\mathrm{M}$, mesh of the prosthesis.

(B) (D) Lack of infiltration into host tissue of the prosthesis consisting of a 3\% neutral

collagen sponge. This dense collagen fibers make the sponge too hard and brittle to

incorporate into the omentum.

Fig. 3. Implantation of the prosthesis into the trachea.

(A) Wrapping of the artificial trachea in pedicled omentum.

(B) Exposure of the intrathoracic trachea after resection of the azygos vein.

(C) Intraoperative view of tracheal reconstruction using pedicled omentum-prosthesis complexes with ventilation in the operative field.

(D) Resection of a $50 \mathrm{~mm}$ segment of trachea and telescopic anastomosis of the remaining trachea with the artificial trachea.

Fig. 4. Bronchoscopic views 1 month after the operation. Neither stenosis nor granulation was present and (A) the luminal surface of the prosthesis appeared glossy and whitish. (B) New blood vessels (arrow) extended from the native to the artificial trachea.(C) Neovascular was confirmed at the center of the lumen at 1 year after transplantation.

Fig. 5. 
(A) Bronchoscopic findings following artificial trachea implantation. Ulceration was observed at the proximal anastomosis site 3 months after surgery.

(B) Regenerated mucosa in the tracheal lumen at the site of previous ulceration.

(C, D) Absence of stenosis and granulation over 2 years, along with complete coverage of the mesh by regenerated tissue.

Fig. 6. Macroscopic findings of the resected artificial trachea 3 months after implantation.

(A) Complete incorporation of the prosthesis into the native trachea.

(B) Complete absence of stenosis.

Fig. 7.

(A) Microscopic examination of a longitudinal section-stained with $\underline{\mathrm{h} H e m a t o x y l i n}$ and eosin stain (original magnification $\times 2$ ). $(\mathbf{B}, \mathbf{D})$ Enlargement of the square areas marked $\mathrm{b}$ and $\mathrm{d}$ in $(\mathrm{A})$, showing regenerated cilia near the anastomosis site and continuity with the native bronchial epithelia. Hematoxylin and eosin staining (original magnification $\times 40$ ). (C) Enlargement of the square area marked $\mathrm{c}$ in $(\mathrm{A})$, showing that the center of the prosthesis is covered with a monolayer of squamous epithelium. Hematoxylin and eosin staining (original magnification $\times 40)$. L, tracheal lumen; M, mesh of the prosthesis.

Fig. 8. Autopsy findings 1 year after replacement, showing incorporation of the prosthesis (arrow) into the native trachea and no signs of infection in the thoracic cavity. 
Video. 1. Digital subtraction angiography of the prosthesis consisting of $1 \%$ collagen.

Video. 2. Bronchoscopic views of the lumen of the prosthesis 3 months after the operation.

\section{Acknowledgments and Disclosures}

Authors have nothing to disclose with regard to commercial support.

\section{References}

(1) Grillo HC. Tracheal replacement: a critical review. Ann Thorac Surg. 2002;73:1995-2004.

(2) Nakanishi R, Shirakusa T, Mitsudomi T. Maximum length of tracheal autografts in dogs. J

Thorac Cardiovasc Surg. 1993;106:1081-1087.

(3) Wright CD, Grillo HC, Wain JC, et al. Anastomotic complications after tracheal resection: prognostic factors and management. J Thorac Cardiovasc Surg. 2004;128:731-739.

(4) Nakamura T, Sato T, Araki M, et al. In situ tissue engineering for tracheal reconstruction using a luminar remodeling type of artificial trachea. J Thorac Cardiovasc Surg. 2009;138:811-819.

(5) Sato T, Araki M, Nakajima N, Omori K, Nakamura T. Biodegradable polymer coating promotes the epithelization of tissue-engineered airway prostheses. J Thorac Cardiovasc Surg. 2010;139:26-31.

(6) Sekine T, Nakamura T, Matsumoto K, et al. Carinal reconstruction with a Y-shaped collagen- 
conjugated prosthesis. J Thorac Cardiovasc Surg. 2000;119:1162-1168.

(7) Okumura N, Nakamura T, Natsume T, Tomihata K, Ikada Y, Shimizu Y. Experimental study on a new tracheal prosthesis made from collagen-conjugated mesh. J Thorac Cardiovasc Surg. $1994 ; 108: 337-345$

(8) Teramachi M, Okumura N, Nakamura T, et al. Intrathoracic tracheal reconstruction with a collagen-conjugated prosthesis: evaluation of the efficacy of omental wrapping. J Thorac Cardiovasc Surg. 1997;113:701-711.

(9) Omori K, Tada Y, Suzuki T, et al. Clinical application of in situ tissue engineering using a scaffolding technique for reconstruction of the larynx and trachea. Ann Otol Rhinol Laryngol. 2008;117:673-678.

(10) Law JX, Liau LL, Aminuddin BS, Ruszymah BH. Tissue-engineered trachea: A review. Int J Pediatr Otorhinolaryngol. 2016;91:55-63.

(11) Gonfiotti A, Jaus MO, Barale D, et al. The first tissue-engineered airway transplantation: 5year follow-up results. Lancet. 2014;383:238-244.

(12) Abouarab AA, Elsayed HH, Elkhayat H, Mostafa A, Cleveland DC, Nori AE. Current Solutions for Long-Segment Tracheal Reconstruction. Ann Thorac Cardiovasc Surg. 2017;23:6675.

(13) Kainuma S, Nakajima K, Miyagawa S, et al. Novel regenerative therapy combined with 
transphrenic peritoneoscopy-assisted omentopexy. Interact Cardiovasc Thorac Surg. 2018;26:993-1001.

(14) Shrager JB, Wain JC, Wright CD, et al. Omentum is highly effective in the management of complex cardiothoracic surgical problems. J Thorac Cardiovasc Surg. 2003;125:526-32.

(15) Collins D, Hogan AM, O'Shea D, Winter DC. The omentum: anatomical, metabolic, and surgical aspects. J Gastrointest Surg. 2009;13:1138-1146.

(16) Platell C, Cooper D, Papadimitriou JM, Hall JC. The omentum. World J Gastroenterol. 2000;6:169-176.

(17) Hamaji M, Kojima F, Koyasu S, et al. Development of a composite and vascularized tracheal scaffold in the omentum for in situ tissue engineering: a canine model. Interact Cardiovasc Thorac Surg. 2014;19:357-362.

(18) Li J, Xu P, Chen H, Yang Z, Zhang Q. Improvement of tracheal autograft survival with transplantation into the greater omentum. Ann Thorac Surg. 1995;60:1592-1596.

(19) Li J, Xu P, Chen H. Successful tracheal autotransplantation with two-stage approach using the greater omentum. Ann Thorac Surg. 1997;64:199-202.

(20) Sakaguchi Y, Sato T, Muranishi Y, et al. Development of a novel tissue-engineered nitinol frame artificial trachea with native-like physical characteristics. J Thorac Cardiovasc Surg. 2018;156:1264-272. 
(21) Teramachi M, Nakamura T, Yamamoto Y, Kiyotani T, Takimoto Y, Shimizu Y. Porous-type tracheal prosthesis sealed with collagen sponge. Ann Thorac Surg. 1997;64:965-969.

(22) Nakada A, Shigeno K, Sato T, Hatayama T, Wakatsuki M, Nakamura T. Optimal dehydrothermal processing conditions to improve biocompatibility and durability of a weakly denatured collagen scaffold. J Biomed Mater Res B Appl Biomater. 2017;105:2301-2307.

(23) Kojima K, Bonassar LJ, Roy AK, Vacanti CA, Cortiella J. Autologous tissue-engineered trachea with sheep nasal chondrocytes. J Thorac Cardiovasc Surg. 2002;123:1177-1184.

(24) Wu W, Cheng X, Zhao Y, Chen F, Feng X, Mao T. Tissue engineering of trachea-like cartilage grafts by using chondrocyte macroaggregate: experimental study in rabbits. Artif Organs. 2007;31:826-834.

(25) Tani G, Usui N, Kamiyama M, Oue T, Fukuzawa M. In vitro construction of scaffold-free cylindrical cartilage using cell sheet-based tissue engineering. Pediatr Surg Int. 2010;26:179-185.

(26) Wurtz A, Porte H, Conti M, et al. Surgical technique and results of tracheal and carinal replacement with aortic allografts for salivary gland-type carcinoma. J Thorac Cardiovasc Surg. 2010;140:387-393.e2.

(27) Kim DH, Choi CB, Yang WJ, et al. Tracheal replacement with fresh and cryopreserved aortic allograft in adult dog. J Surg Res. 2012;175:199-206.

(28) Wurtz A, Hysi I, Zawadzki C, et al. Construction of a tube-shaped tracheal substitute using 
fascial flap-wrapped revascularized allogenic aorta. Eur J Cardiothorac Surg. 2012;41:663-668.

(29) Neville WE, Bolanowski JP, Kotia GG. Clinical experience with the silicone tracheal prosthesis. J Thorac Cardiovasc Surg. 1990;99:604-612; discussion 12-3.

(30) Shimizu Y, Tamura K, Kato H, Teramatsu T, Hino T. Study on the artificial trachea using mesh. Jpn J Artif Organs 1983;486-489.

(31) Okumura N, Teramachi M, Takimoto Y, Nakamura T, Ikada Y, Shimizu Y. Experimental reconstruction of the intrathoracic trachea using a new prosthesis made from collagen grafted mesh. ASAIO J. 1994;40:M834-839.

(32) Liu Y, Lu T, Zhang Y, Qiao Y, Xi J, Wang Q. Collagen-conjugated tracheal prosthesis tested in dogs without omental wrapping and silicone stenting. Interact Cardiovasc Thorac Surg. 2016;23:710-715.

(33) Yokomise H, Inui K, Wada H, Ueda M, Hitomi S, Itoh H. Split transplantation of the trachea: a new operative procedure for extended tracheal resection. J Thorac Cardiovasc Surg. 1996;112:314-318.

(34) Klepetko W, Marta GM, Wisser W, et al. Heterotopic tracheal transplantation with omentum wrapping in the abdominal position preserves functional and structural integrity of a human tracheal allograft. J Thorac Cardiovasc Surg. 2004;127:862-867.

(35) Luo X, Liu Y, Zhang Z, et al. Long-term functional reconstruction of segmental tracheal 
defect by pedicled tissue-engineered trachea in rabbits. Biomaterials. 2013;34:3336-3344. 
TABLE 1. Results of long segment intrathoracic tracheal reconstruction in individual dogs

\begin{tabular}{|c|c|c|c|c|c|}
\hline Dog no. & Stenosis & Dehiscence & Observation (months) & Epithelization & Remarks \\
\hline 1 & $(-)$ & $(-)$ & 3 & $100 \%$ & $\begin{array}{l}\text { Sacrificed at } 3 \text { months. Bowel obstruction due to diaphragmatic hernia } \\
\text { was detected. }\end{array}$ \\
\hline 2 & $(-)$ & $(-)$ & 6 & $100 \%$ & Sudden death at 6 months. There were no airway complications. \\
\hline 3 & $(-)$ & $(-)$ & 12 & $95 \%$ & $\begin{array}{l}\text { Sacrificed at } 12 \text { months. Small mesh exposure observed at the proximal } \\
\text { anastomosis site. }\end{array}$ \\
\hline 4 & $(-)$ & $(-)$ & 12 & $95 \%$ & $\begin{array}{l}\text { Sacrificed at } 12 \text { months. Small mesh exposure observed at the distal } \\
\text { anastomosis site. }\end{array}$ \\
\hline 5 & $(-)$ & $(-)$ & 14 & $100 \%$ & \\
\hline 6 & $(-)$ & $(-)$ & 16 & $100 \%$ & Sacrificed at 16 months due to appetite loss. \\
\hline 7 & $(-)$ & $(-)$ & 22 & $100 \%$ & \\
\hline 8 & $(-)$ & $(-)$ & 27 & $100 \%$ & \\
\hline 9 & $(-)$ & $(-)$ & 30 & $100 \%$ & Sudden death at 30 months due to a hemorrhagic gastric ulcer. \\
\hline
\end{tabular}


